OPEN ACCESS

Edited by:

Marco Pombi,

Sapienza University of Rome, Italy

Reviewed by:

Adnan Hodžic,

University of Veterinary Medicine

Vienna, Austria

Jairo Mendoza Roldan,

University of Bari Aldo Moro, Italy

${ }^{*}$ Correspondence:

Christina Strube

christina.strube@tiho-hannover.de

Specialty section: This article was submitted to

Parasitology,

a section of the journal

Frontiers in Veterinary Science

Received: 10 September 2020 Accepted: 18 November 2020

Published: 10 December 2020

Citation:

Springer A, Glass A, Topp A-K and Strube C (2020) Zoonotic Tick-Borne

Pathogens in Temperate and Cold Regions of Europe-A Review on the

Prevalence in Domestic Animals.

Front. Vet. Sci. 7:604910.

doi: 10.3389/fvets.2020.604910

\section{Zoonotic Tick-Borne Pathogens in Temperate and Cold Regions of Europe-A Review on the Prevalence in Domestic Animals}

\author{
Andrea Springer, Antje Glass, Anna-Katharina Topp and Christina Strube* \\ Institute for Parasitology, Centre for Infection Medicine, University of Veterinary Medicine Hannover, Hanover, Germany
}

Ticks transmit a variety of pathogens affecting both human and animal health. In temperate and cold regions of Europe (Western, Central, Eastern, and Northern Europe), the most relevant zoonotic tick-borne pathogens are tick-borne encephalitis virus (TBEV), Borrelia spp. and Anaplasma phagocytophilum. More rarely, Rickettsia spp., Neoehrlichia mikurensis, and zoonotic Babesia spp. are identified as a cause of human disease. Domestic animals may also be clinically affected by these pathogens, and, furthermore, can be regarded as sentinel hosts for their occurrence in a certain area, or even play a role as reservoirs or amplifying hosts. For example, viraemic ruminants may transmit TBEV to humans via raw milk products. This review summarizes the role of domestic animals, including ruminants, horses, dogs, and cats, in the ecology of TBEV, Borrelia spp., A. phagocytophilum, Rickettsia spp., N. mikurensis, and zoonotic Babesia species. It gives an overview on the (sero-)prevalence of these infectious agents in domestic animals in temperate/cold regions of Europe, based on 148 individual prevalence studies. Meta-analyses of seroprevalence in asymptomatic animals estimated an overall seroprevalence of $2.7 \%$ for TBEV, $12.9 \%$ for Borrelia burgdorferi sensu lato (s.l.), $16.2 \%$ for $A$. phagocytophilum and $7.4 \%$ for Babesia divergens, with a high level of heterogeneity. Subgroup analyses with regard to animal species, diagnostic test, geographical region and decade of sampling were mostly non-significant, with the exception of significantly lower B. burgdorferi s.l. seroprevalences in dogs than in horses and cattle. More surveillance studies employing highly sensitive and specific test methods and including hitherto non-investigated regions are needed to determine if and how global changes in terms of climate, land use, agricultural practices and human behavior impact the frequency of zoonotic tick-borne pathogens in domestic animals.

Keywords: Borrelia, Rickettsia, Anaplasma, Babesia, Neoehrlichia mikurensis, tick-borne encephalitis, tick-borne diseases, vector-borne diseases

\section{INTRODUCTION}

Many tick-borne diseases (TBDs) are so-called meta-zoonoses, i.e., they may be transmitted to humans as well as animals via their invertebrate tick host (1). In temperate/cold regions of Europe, the hard tick Ixodes ricinus is the most important vector of TBDs in terms of both animal and human (public) health, followed by Dermacentor reticulatus and Dermacentor marginatus (2). 
Meta-zoonotic pathogens transmitted by $I$. ricinus include tickborne encephalitis virus (TBEV), Borrelia spp., Anaplasma phagocytophilum, Rickettsia spp., Neoehrlichia mikurensis and zoonotic Babesia spp., while ticks of the genus Dermacentor may transmit Rickettsia spp. to both animals and humans, among others (3). In addition, D. reticulatus is now also recognized as a vector for $\mathrm{TBEV}(4)$.

Ixodes ricinus has a broad host spectrum, including birds, various wild and domestic animals as well as humans, and occurs in a wide variety of habitats throughout Europe, as far north as $66^{\circ} \mathrm{N}$ (Norway), close to the Arctic Circle (5). The species' range has continuously expanded northward as well as into higher altitudes during the past decades, probably driven by climatic and environmental changes $(6,7)$. Similarly, the distribution of $D$. reticulatus is expanding in several European countries $(8,9)$. A northward spread has been documented in the Baltic countries (10) as well as in Germany (11), but the species has not been documented in Scandinavia to date. In contrast, the distribution of $D$. marginatus seems to be comparatively stable with a northern distribution limit at $\sim 51^{\circ} \mathrm{N}$ in central Germany (11). In addition to the range expansion of different tick species, changes in human behavior toward more outdoor activities increase the risk of tick bites (2).

In consequence, the incidence and public health burden of TBDs seem to be increasing in Europe. Lyme borreliosis (LB), caused by spirochaetes of the Borrelia burgdorferi sensu lato (s.l.) complex and transmitted primarily by I. ricinus, is the most common TBD in humans in the Northern Hemisphere. In Europe, annual incidence rates vary between 0.001 and 464 cases $/ 100,000$ inhabitants (12). In the Netherlands, a more than 2 -fold increase of medical consultations and hospital admissions due to LB was noted from 1994 to 2005 (13). A similar increase in diagnosed LB cases was observed in the United Kingdom from 1998 to 2016 (14). Likewise, the incidence of tick-borne encephalitis, a flavivirus infection transmitted also primarily by $I$. ricinus, has increased significantly since the year 1990 in several European countries (15). The geographic pattern of this disease is also changing, with new transmission foci emerging in previously unaffected regions and countries, e.g., in the Netherlands in 2016 (16) and in the United Kingdom in 2018 (17).

In addition to rising disease incidences, several new tick-borne pathogens have been described in recent decades (18). Although known already since 1995 (19), pathogenicity of Borrelia miyamotoi, a tick-transmitted relapsing-fever spirochaete, was first reported in 2011 (20). Similarly, N. mikurensis was isolated from ticks and mammals (21) years before being recognized as a human (22) and probably veterinary (23) pathogen. Furthermore, the list of emerging zoonotic tick-borne pathogens relevant in Europe includes several Rickettsia spp. (18) and Babesia spp. (24). Borrelia miyamotoi, N. mikurensis, Rickettsia helvetica and the relevant zoonotic Babesia spp. are all transmitted by I. ricinus, which constitutes the main vector of zoonotic TBDs in central and northern Europe. In contrast, D. marginatus, the vector of Rickettsia slovaca, has a rather limited geographic distribution, and D. reticulatus, the vector of Rickettsia raoultii, rarely bites humans (11). Therefore, these tick species are of minor importance regarding zoonotic infections.
Domestic animals may also be clinically affected by these pathogens, and, furthermore, can be regarded as sentinel hosts for their occurrence in a certain area, or even play a role as reservoir hosts. Additionally, viraemic ruminants may directly transmit TBEV to humans via raw milk products, causing large outbreaks (25). In this review, we summarize the role of domestic animals, including ruminants, horses, dogs, and cats, in the ecology of TBEV, Borrelia spp., A. phagocytophilum, Rickettsia spp., N. mikurensis, and zoonotic Babesia species. Unlike for humans, no systematic surveillance of TBDs in domestic animals exists, making it difficult to assess whether the patterns of increasing disease incidence observed in humans can also be found in other species. Therefore (sero-)prevalence data on the mentioned pathogens in domestic animals in temperate and cold regions of Europe are compiled to analyze temporal and regional trends, the influence of the utilized diagnostic test and to identify knowledge gaps requiring further attention.

\section{METHODS}

\section{Literature Survey}

Systematic literature search on (sero-)prevalence data in temperate and cold regions of Europe [Northern, Western, Central, and Eastern Europe (excluding Russia); see Figure 1 for included countries] was conducted in the PubMed database in May and July 2020, using combinations of the term "prevalence" with each of "animals," "ruminants," "horses," "dogs," "cats" and each of "TBEV," "Borrelia," "Anaplasma," "Rickettsia," "Neoehrlichia," and "Babesia."

Further records were obtained by searching the bibliographies of relevant articles and via incidental findings using other databases, e.g., Google Scholar. Original publications in English and different national languages (e.g., German, French, if available) were included. Articles that did not refer to the considered geographical region, did not contain (sero-)prevalence data, e.g., clinical case reports, or that presented data from only one herd/flock, were excluded.

\section{Meta-Analyses}

For TBEV, B. burgdorferi s.l., A. phagocytophilum and Babesia divergens seroprevalence, data based on healthy/asymptomatic animals or randomly selected diagnostic samples were subjected to meta-analyses, to gain a comprehensive picture on TBD prevalence in the general domestic animal population. As the number of studies retrieved for the remaining pathogens was low, no meta-analyses were conducted. If studies reported data on healthy and symptomatic groups, only data referring to the healthy group were extracted, because seroprevalences in symptomatic animals may be higher than in the general population.

Random-effects meta-analysis of proportions was conducted with the package "meta" (v. 4.13-0) (26) in R v. 4.0.2 (27), using the inverse variance method with logit transformation and restricted maximum likelihood estimation of the between-study variance $\left(\tau^{2}\right)$. To assess heterogeneity between studies, $Q$-tests were performed and the $I^{2}$ statistic was assessed, with values $\geq 50 \%$ considered heterogeneous. To evaluate possible sources 


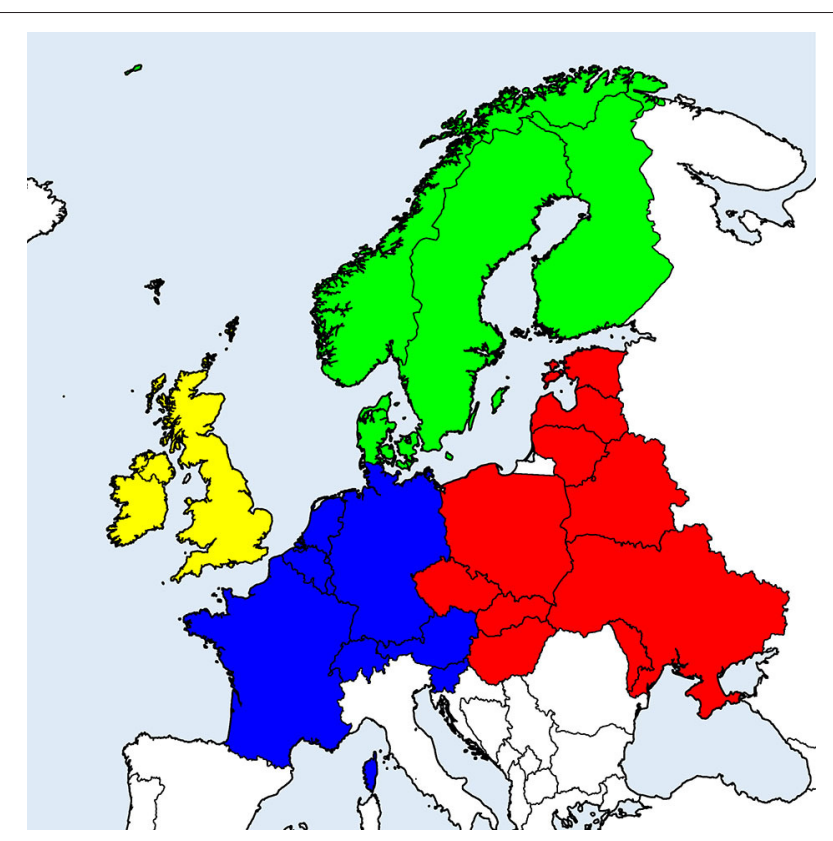

FIGURE 1 | European countries considered in the literature survey on (sero-)prevalence of tick-borne zoonotic diseases in domestic animals. Geographical regions are indicated by different colors: Scandinavia (green), British Isles (yellow), Western continental (blue), and Eastern continental Europe (red).

of heterogeneity, subgroup analyses were performed according to animal species, type of diagnostic test used, geographical region and decade of sampling. For analyses according to geographical region, the considered countries were classified into Eastern or Western continental Europe, Scandinavia or British Isles (Figure 1). In cases when studies did not report the period of sampling, it was assumed that the decade of sampling corresponded to the decade of data publication. In subgroup analyses, a common $\tau^{2}$ was assumed across subgroups.

If studies reported more than one seroprevalence rate, referring to different species, geographic regions, or data acquisition periods, these were considered separately. Since observational prevalence studies are unlikely to suffer from publication bias, i.e., low prevalence rates have a similar probability of being published as higher prevalence rates (28), no assessment of publication bias was performed.

\section{RESULTS}

In total, 7,552 publications were assessed for eligibility and 7,404 were excluded because they were not relevant with regard to the considered pathogens or geographical range, consisted of clinical case reports referring to single animals or herds, dealt only with imported animals or did not contain sufficient data. The selection process during the literature survey is depicted in Figure 2, with a final dataset containing 148 articles. Of these, 65 reported data on A. phagocytophilum, 55 on B. burgdorferi s.l., 35 on TBEV, 18 on zoonotic Babesia species, 9 on Rickettsia spp., and 5 on $N$. mikurensis. Some publications contained data on more than one of these pathogens.

An overview of the roles of domestic animals regarding the considered tick-borne pathogens is given in Figure 3. In the following, these roles as well as the (sero-)prevalence rates are discussed in detail for each infectious agent.

\section{Tick-Borne Encephalitis Virus}

Tick-borne encephalitis is regarded as the most important arthropod-borne viral disease in Europe (29). It is caused by a flavivirus which is mainly transmitted by I. ricinus, but the vector potential of $D$. reticulatus has also been shown (4). Unlike other tick-associated pathogens, it is not consistently distributed throughout the range of its vectors, but occurs in a patchy pattern in delimited geographic areas, termed microfoci or "hotspots." In these foci, it circulates between rodents and ticks and occasionally spills over to domestic animals and humans (29). In recent decades, a geographical spread of the virus has been observed in Europe with new transmission foci having recently emerged in the Netherlands (16) and the United Kingdom (17).

TBEV may cause severe neurologic disease in humans, horses, dogs, and probably also in ruminants (Figure 3). Furthermore, most domestic animals are regarded as useful sentinels for human TBE risk (30), with the exception of cats for which no data exist, explaining the comparatively large number of retrieved studies.

In total, 36 studies were retrieved (eight containing data on cattle, seven on sheep, 10 on goats, seven on horses, and 13 on dogs). As cross-reactions with other flaviviruses (e.g., West Nile virus, Louping Ill virus) in serological tests are common, only studies which confirmed positive samples via seroneutralisation test (SNT), considered the gold standard of TBEV serology (31), were included in the meta-analysis of seroprevalence $(N=20$, with 39 animal cohorts). Therefore, subgroup analysis according to diagnostic test was not performed. The estimated overall prevalence was $2.8 \%$, with a significant level of heterogeneity $\left(I^{2}=95.8 \%\right.$; 95\% CI: 95.0-96.5\%; $\left.P<0.001\right)$. No significant differences between animal species $\left(\chi^{2}=2.6, \mathrm{df}=4, P=0.622\right.$; Figure 4) nor between decades $\left(\chi^{2}=4.4 \mathrm{df}=2, P=0.110\right)$ or regions $\left(\chi^{2}=1.9, \mathrm{df}=2, P=0.390\right)$ were found.

\section{Ruminants}

Domestic ruminants develop viraemia upon TBEV infection, which usually lasts a few days, but remain mostly asymptomatic (32). However, they excrete TBEV in milk during the viraemic phase, potentially leading to human infection via raw milk products like unpasteurized milk or raw milk cheese. In goat milk, infective virus can be detected for up to 19 days post infection (33). Such alimentary transmission often causes clusters of cases [e.g., $(34,35)]$ and is regarded as the second most important route of human infection (25).

In addition, a few clinical cases of neurologic disease in small ruminants due to TBEV have been described $(36,37)$. Possibly, clinical cases in these species are often overlooked or misinterpreted, e.g., as Listeria monocytogenes infection (36), and may be more common than previously thought. Furthermore, ruminants are regarded as useful sentinel species for TBEV occurrence. They have a comparatively restricted range of 

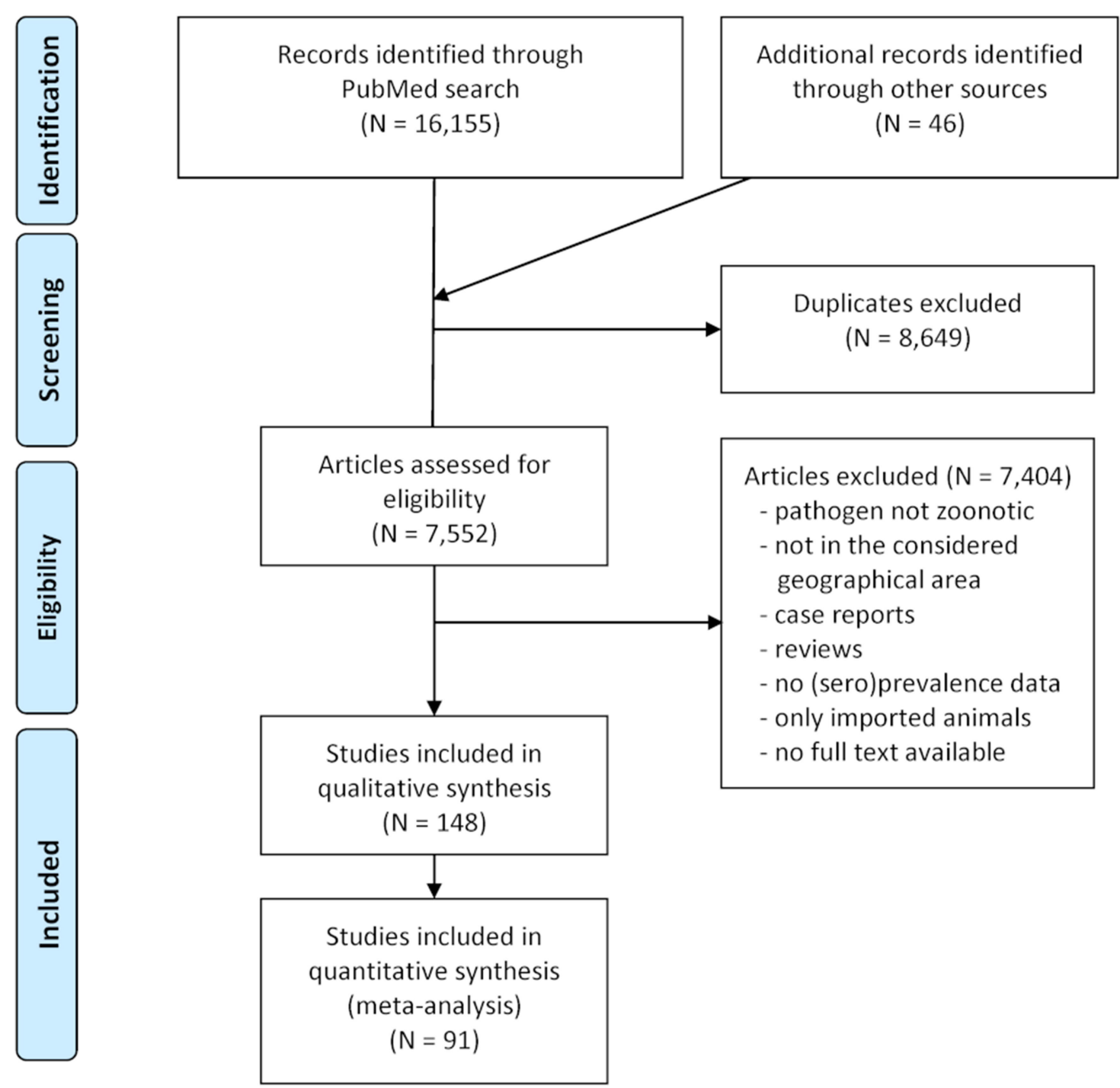

Articles excluded $(\mathrm{N}=7,404)$

- pathogen not zoonotic

- not in the considered geographical area

- case reports

- reviews

- no (sero)prevalence data

- only imported animals

- no full text available

FIGURE 2 | PRISMA flow-chart detailing the selection process applied during the literature survey.

activity, i.e., they travel less than dogs and horses, and show persistence of antibodies for up to 28 months post infection (38). Therefore, several studies have been conducted on TBEV seroprevalence in domestic ruminants, particularly in goats and sheep (Supplementary Table 1).

Studies on cattle ( $N=8$, two from Norway, one each from Belgium, Finland, Hungary, Lithuania, the Netherlands, and Poland) reported seroprevalences ranging from $0.0 \%$ in the Netherlands (39) to $26.5 \%$ in Hungary (40) (Supplementary Table 1). One Norwegian study assessed TBEV excretion in milk and found 5.4\% PCR-positive samples (41).

Seven studies reported seroprevalence data on sheep (two each from Sweden and Germany, one each from Hungary, Lithuania, and Slovakia), with values ranging from $0.0 \%$ in northern Germany (42) to $25.6 \%$ in farms with high lamb morbidity and mortality in Sweden (43). However, no confirmation of positive samples by SNT was performed in the latter study, so that crossreactions with other flavivirus infections, e.g., louping ill, which has previously been detected in Norwegian sheep (44), cannot be ruled out. Seroprevalence in the 10 studies reporting data on goats (four from Germany, one each from Austria, Lithuania, the Netherlands, and Poland) ranged from $0.0 \%$ in the northern German federal state of Mecklenburg-Western Pomerania, which is not regarded as a TBEV risk area (45), to $14.6 \%$ in the Swiss canton of Ticino (46). Direct pathogen detection in sheep and goats, e.g., by PCR, was not reported in the considered studies.

\section{Horses}

As in ruminants, TBEV infections in horses are mostly asymptomatic (47). However, cases of encephalomyelitis with symptoms such as anorexia, ataxia, spasms, and epileptic seizures 


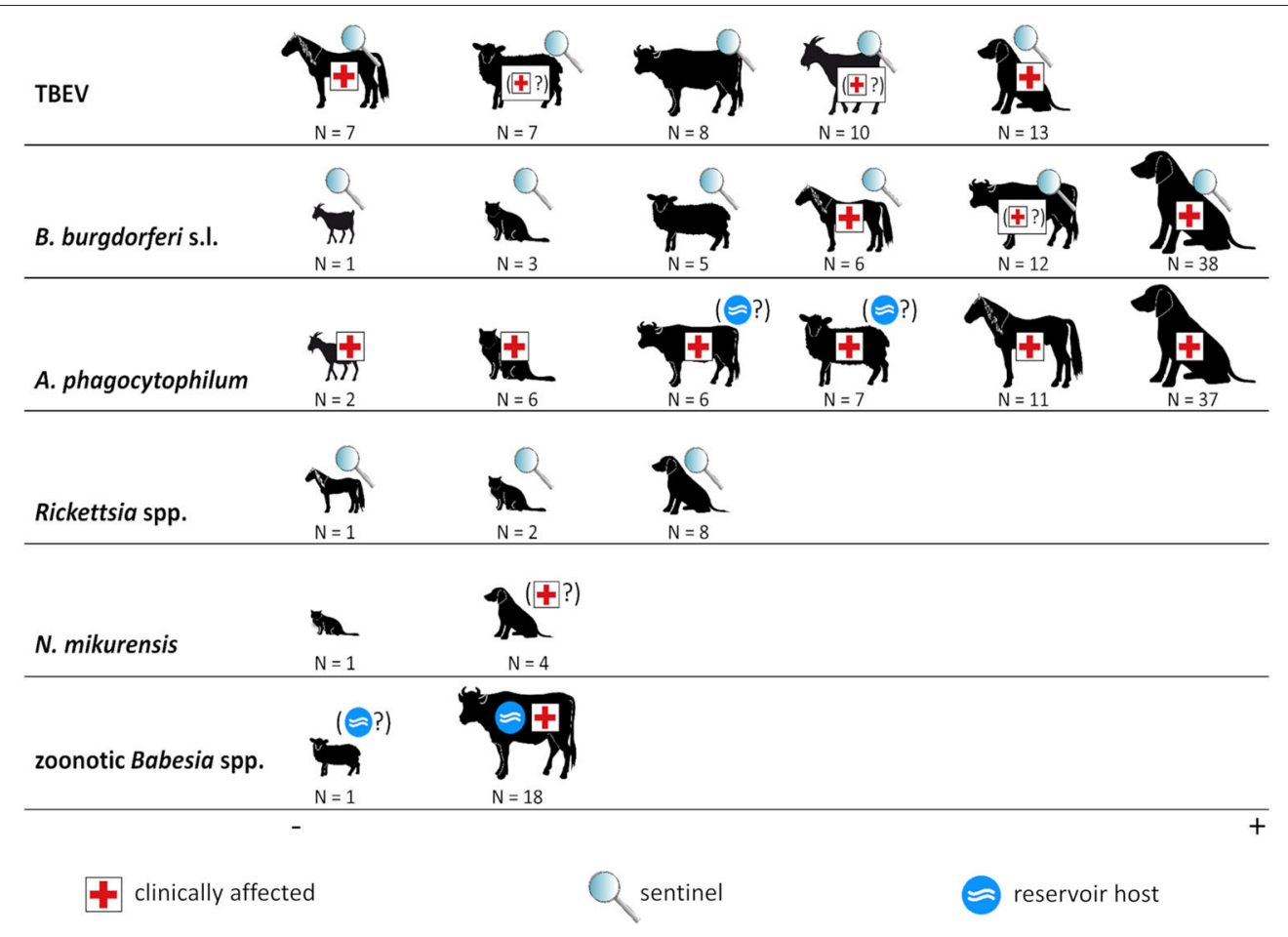

FIGURE 3 | Animal species and tick-borne pathogens. The size of animal icons corresponds to the number of studies. Symbols indicate the role of each animal species in the ecology of the respective pathogen. Symbols in brackets indicate that this role is uncertain. Borrelia miyamotoi is not shown as no (sero-)prevalence studies regarding this pathogen in domestic animals were retrieved.

have been described $(48,49)$. Mild neurologic deficits may persist after recovery (49).

The literature survey resulted in the identification of seven studies on TBEV seroprevalence in horses (three from Germany, two from Austria, one each from Hungary and Slovakia; Supplementary Table 1), with values ranging from $0.0 \%$ in Hungary (40) to $33.0 \%$ in a TBEV risk area in Bavaria, Germany (49). All of these studies confirmed positive samples by SNT (Supplementary Table 1).

\section{Dogs and Cats}

In dogs, a similar TBE disease course as in humans with severe, often fatal neurological manifestations due to encephalitis has been described (50). However, high seroprevalence rates in some areas indicate that only a small proportion of infected dogs develops disease, whereas most infections remain asymptomatic (47). Because dogs usually accompany their owners, they are regarded as valuable sentinels for human TBEV risk. However, as companions of man, they often have a travel history, which makes assessment of TBE risk in a certain area based on dog sera less reliable compared to other sentinel animals (30).

In the present survey, 13 studies presenting data on TBEV (sero-)prevalence in dogs were identified (three from Germany, two from the Czech Republic, one each from Austria, Belgium, Denmark, Finland, the Netherlands, Norway, and Poland, and one study reporting data on dogs from different European countries; Supplementary Table 1). Seroprevalence ranged from
$0.0 \%$ in the Netherlands (39) to $53.6 \%$ in dogs with neurological signs in Germany (51). However, positive results were not confirmed by SNT in the latter study, so that the possibility of cross-reactions with other flaviviruses needs to be considered. Cross-reactions also appear probable in light of the high seroprevalence detected in healthy dogs $(30.4 \%)$ in the same study, compared with an estimated overall seroprevalence of $1.4 \%$ based on asymptomatic dogs when positive samples were confirmed by SNT (Figure 4). Nevertheless, another study including dogs with neurological illness determined a TBEV infection rate of $12.6 \%$ by real-time PCR (52), indicating that TBEV prevalence among dogs with neurologic disease may be substantial.

No cases of TBEV infections in cats have been published to date. Preliminary data of a study including more than 200 cats from a TBE-endemic area in Germany showed no seropositive individuals (personal communication with Martin Pfeffer, Institute of Animal Hygiene and Veterinary Public Health, University of Leipzig, and Gerhard Dobler, Bundeswehr Institute of Microbiology, Munich).

\section{Borrelia burgdorferi s.l.}

The B. burgdorferi s.l. complex currently comprises 22 recognized species of spirochaetal bacteria (53), at least nine of which occur in European tick populations (54). Of those, Borrelia afzelii and Borrelia garinii are the most prevalent and constitute the most important agents of human LB throughout Europe $(54,55)$. 


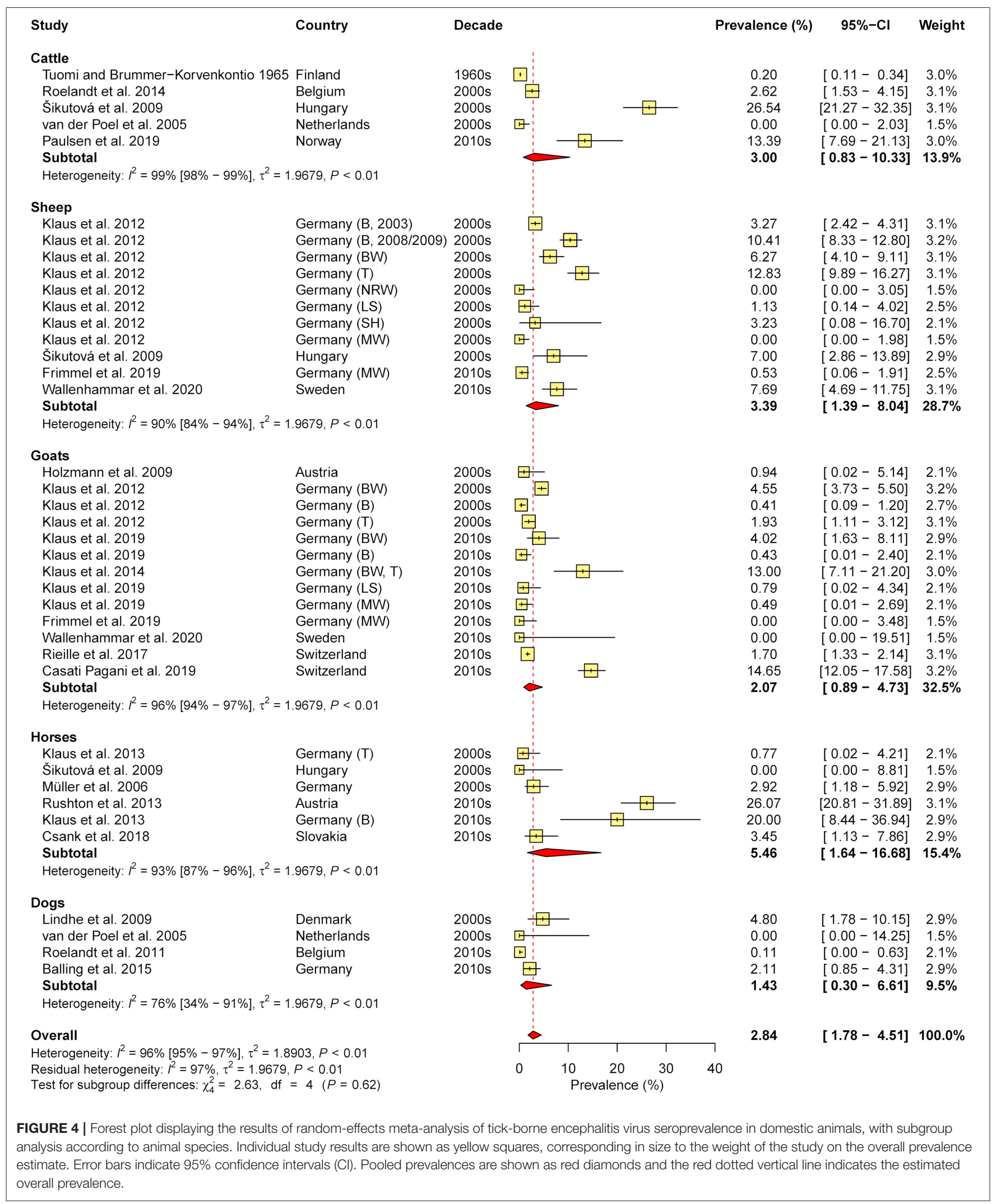


Borrelia burgdorferi s.l. predominantly circulates between Ixodes ticks (in Europe I. ricinus) and wild mammals (e.g., B. afzelii, $B$. bavariensis), birds (e.g., B. garinii, B. valaisiana), or reptiles (B. lusitaniae) as reservoir hosts (56).

In total, 53 studies reporting $B$. burgdorferi s.l. (sero-)prevalence rates in domestic animals were retrieved (Supplementary Table 2). Since a vaccine against borreliosis in dogs was introduced to the European market at the end of the 1990s, it is important to distinguish between vaccinated and naturally exposed dogs when evaluating seroprevalence (57). Antibodies against the variable major protein-like sequence expressed (VlsE) and one of its invariable regions, the C6 peptide, as well as the outer surface protein OspF indicate natural exposure, because these antigens are not present in the available vaccines (58). Therefore, dog seroprevalence studies conducted after 1995 were only considered in the meta-analysis if they were based on a C6 or OspF assay.

Meta-analysis of seroprevalence, including 48 animal cohorts (13 cattle, 3 sheep, 9 horse, $21 \mathrm{dog}$, and 2 cat cohorts) from 30 publications, estimated an overall seroprevalence of $12.4 \%$ (95\% CI: $0.1-17.2 \%)$ with a significant level of heterogeneity $\left(I^{2}\right.$ $=98.0 \%$; 95\% CI: 97.8-98.3\%; $P<0.001)$. Subgroup analysis indicated a significant effect of animal species $\left(\chi^{2}=24.4, \mathrm{df}=\right.$ $4, P<0.001)$, with a lower seroprevalence in $\operatorname{dogs}(5.8 \%, 95 \% \mathrm{CI}$ : $3.7-8.9 \%)$ than in cattle (23.6\%, 95\% CI: $14.8-35.4 \%)$ and horses (22.5\%, 95\% CI: 12.6-36.9\%; Figure 5). In contrast, there were no significant differences according to decade $\left(\chi^{2}=4.7, \mathrm{df}=3\right.$, $P=0.193)$, diagnostic test used $\left(\chi^{2}=3.3, \mathrm{df}=2, P=0.193\right)$, and geographical region $\left(\chi^{2}=2.9, \mathrm{df}=2, P=0.230\right)$ when analyzing all 48 cohorts.

Due to the significant effect of animal species, further analyses were conducted on the data subset for dogs, as this species had the largest sample size (21 cohorts from 16 studies). In the data subset on dogs, a significant effect of diagnostic test was found $\left(\chi^{2}=7.5, \mathrm{df}=2, P=0.023\right)$, with a lower seroprevalence determined by a C6-based rapid ELISA (3.1\%, 95\% CI: $1.5-$ $6.0 \%)$ than by conventional ELISA (11.2\%, 95\% CI: $6.0-20.0 \%$; Supplementary Figure 1). In contrast, no significant effect of geographical region $\left(\chi^{2}=2.4, \mathrm{df}=2, P=0.302\right)$ nor decade of sampling $\left(\chi^{2}=3.5\right.$, df $\left.=3, P=0.324\right)$ was found in dogs.

\section{Ruminants}

Species-specific Borrelia-host associations are thought to be primarily driven by variation in resistance toward host defense mechanisms, particularly complement (59). Different species of the B. burgdorferi s.l. complex differ in their level of susceptibility toward inactivation of sera from certain animals in vitro [e.g., $(60,61)]$. Notably, all tested members of the B. burgdorferi s.l. complex display high sensitivity toward serum complement from several ruminant species, including deer, bison, and cattle (59). Thus, these species seem to be irrelevant as B. burgdorferi s.l. reservoirs. In contrast, ticks feeding on these species may even lose their Borrelia infection, as suggested by prevalence patterns in engorged ticks recovered from deer, cattle and goats vs. prevalence in questing ticks $(62,63)$. Therefore, it has been suggested that an increase in grazing domestic ruminants may lower the risk of Lyme disease acquisition in a certain area (62).
However, this does not apply to all ruminants, as several $B$. burgdorferi s.l. species are resistant toward serum of sheep and their wild relatives, the mouflon (59), and sheep may sustain natural $B$. burgdorferi s.l. cycles in the absence of other tick hosts (64).

Despite their apparent ability to eliminate B. burgdorferi s.l. spirochaetes, active $B$. burgdorferi sensu stricto (s.s.), and $B$. afzelii infections with associated symptoms (skin erythema, fever, acute lameness due to arthritis) have been described in cattle in rare cases $(65,66)$. Other studies draw a connection between serological evidence of $B$. burgdorferi s.l. infection and clinical signs such as lameness and swollen joints (67), but causality in these cases is extremely questionable. Experimental infections of cattle with B. burgdorferi s.s., B. garinii, and B. afzelii produced no clinical signs (68). Similarly, clinical manifestations of LB have been suspected in sheep (69), but experimental infections failed to produce any symptoms (70). Regarding goats, neither clinical cases nor infection experiments have been published to the authors' knowledge. Overall, clinical relevance of B. burgdorferi s.l. for ruminants is questionable. Nevertheless, they seroconvert upon contact with the pathogen (68) and may therefore be regarded as sentinels for pathogen presence.

In the present survey, 12 studies reporting seroprevalence rates in cattle were retrieved (six from Germany, one each from France, Poland, Slovakia, Sweden, and Switzerland and one reporting data from Poland as well as Slovakia; Supplementary Table 2). Reported seroprevalences ranged from $1.1 \%$ in northern Sweden (71) to $66.0 \%$ in Germany (72). Five studies reported data on sheep (two from Sweden, one each from France, Norway and Slovakia), with seroprevalences ranging from $0.0 \%$ in healthy sheep in central Sweden to $84.6 \%$ in lambs with arthritis on the island of Gotland, Sweden (71). The highest seroprevalence in asymptomatic sheep was determined in France (56.5\%) (73). The only study containing data on goats reported a $17.2 \%$ seroprevalence rate in this species in Slovakia (74). Direct pathogen detection, e.g., by PCR, was not reported for ruminants in the considered studies.

\section{Horses}

In horses, a broad spectrum of clinical manifestations, including arthritis, lameness, anterior uveitis, encephalitis, and abortion, has been attributed to B. burgdorferi s.l. infection; however, in many cases a causal relationship has not been conclusively proven (75). Experimental inoculations of ponies led to systemic infection, persisting for at least 9 months, but did not induce any clinical signs nor histopathological alterations, except for skin lesions $(76,77)$. More recently, however, several case reports of equine neuroborreliosis with $B$. burgdorferi s.l. detection in the central nervous system have been published (78-81). In one of these studies, the species was identified as $B$. burgdorferi s.s. and high spirochaetal loads were demonstrated in tissues with inflammation (79). However, all of these cases occurred in North America, thus, it remains unclear if European $B$. burgdorferi s.s. isolates and other LB agents are capable of causing clinical manifestations in horses. Evidence from in vitro studies suggests that all tested B. burgdorferi s.l. species are susceptible to inactivation by equine complement, 


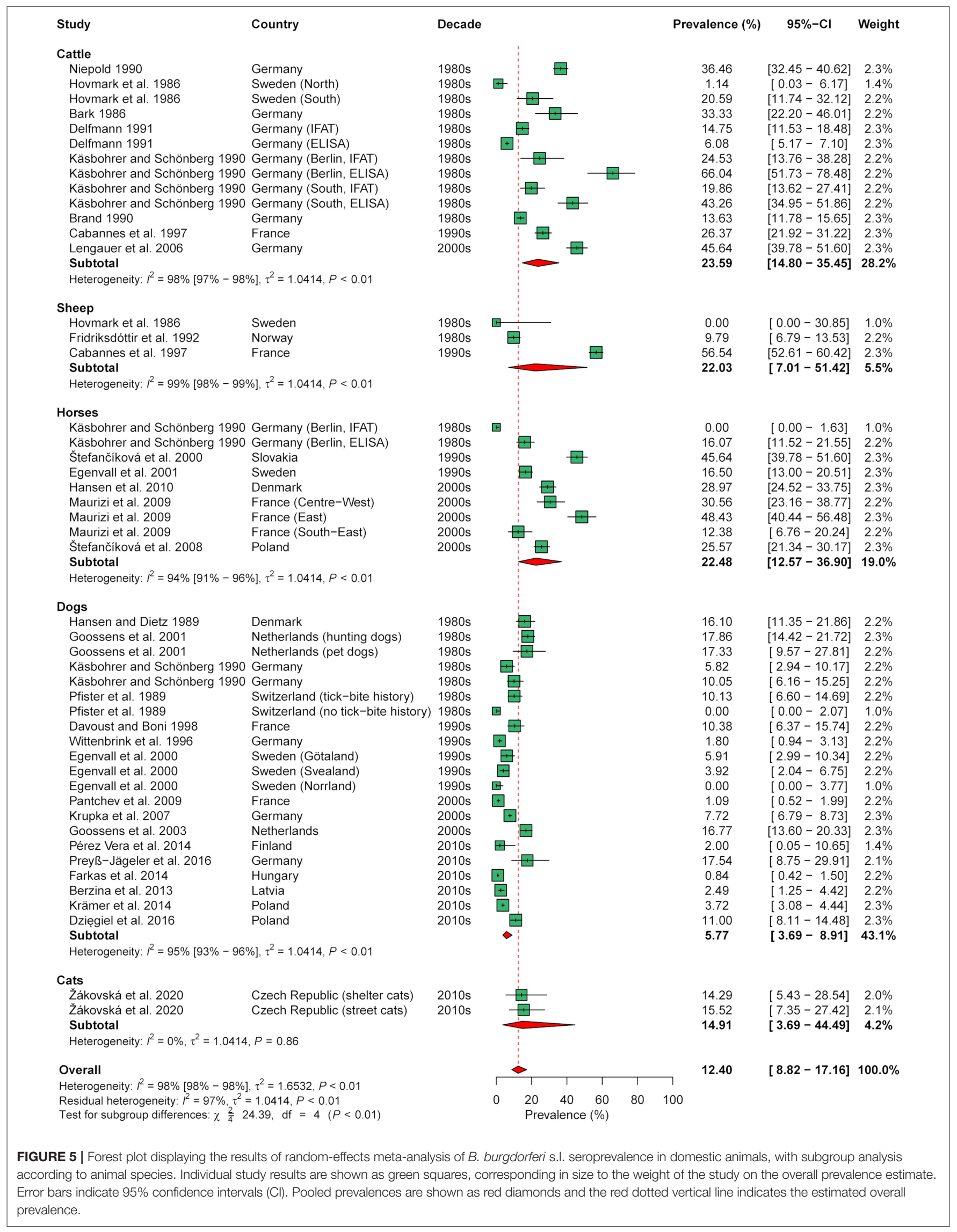


except for B. burgdorferi s.s. which displays an intermediate sensitivity (59).

In contrast to the paucity of conclusive clinical equine borreliosis cases in Europe, six studies evaluating seroprevalence rates in this species were retrieved (one each from Poland, Denmark, France, Germany, and Sweden and one reporting data from both Poland and Slovakia). Reported seroprevalence rates ranged from $12.4 \%$ in south-eastern to $48.4 \%$ in eastern France (82). Studies employing direct detection methods, e.g., PCR, were not retrieved.

\section{Dogs and Cats}

According to a consensus statement by the American College of Veterinary Internal Medicine (ACVIM), most B. burgdorferi s.l. seropositive dogs and cats display no clinical signs, neither after natural nor experimental infections (58). A small subset of dogs, however, may develop arthritis due to B. burgdorferi s.s. infection, as demonstrated by experimental infections (83-85). Furthermore, nephritis is putatively associated with B. burgdorferi s.s. infections, however, well-documented case reports are rare and no experimental studies exist in this regard (58). To the authors' knowledge, evidence for clinical manifestations due to other species of the B. burgdorferi s.l. complex in dogs is lacking to date, although $B$. afzelii has been isolated from a dog with clinical signs attributable to LB in Europe (86). Furthermore, DNA of B. valaisiana and B. garinii has been amplified from symptomatic dogs $[(87,88)$; see below]. In experimental studies, dogs have been shown to transmit borreliae to ticks, indicating a potential reservoir function (89). However, in the light of abundant wild reservoir hosts, such as rodents and birds, the impact of pet dogs on the natural epidemiological cycle is probably neglectable (90).

Cats have been infected experimentally and show seroconversion, but no clinical signs of infection $(91,92)$. Some case reports have attributed clinical signs in cats, such as cardiac arrhythmia and lameness, to B. burgdorferi s.l. infection based on seropositivity, PCR detection of the pathogen and/or resolution upon antibiotic treatment $(93,94)$; however, as in many other cases a causative relationship remains speculative.

Nevertheless, seroprevalence in domestic dogs and cats may provide an estimate of human LB risk. A strong association was found between canine seroprevalence and mean LB incidence on county level in the United States of America (95).

In the present survey, 38 studies reporting B. burgdorferi s.l. (sero-)prevalences in dogs were compiled (seven each from Germany and Poland, four from Sweden, three each from the Netherlands, Slovakia, and Switzerland, two each from the Czech Republic and France and one each from Austria, Denmark, Finland, Hungary, Latvia, Lithuania, and Norway). Seroprevalences ranging from $0.0 \%$ in northern Norway (96) to $57.5 \%$ in Bernese Mountain dogs in Switzerland (97) were reported. This dog breed seems to have a predisposition for $B$. burgdorferi s.l. infection, as demonstrated by several studies (9799), although the reasons for this predisposition are unknown (58). As reported above, a significant effect of the utilized diagnostic test on the seroprevalence in dogs was found (section Tick-Borne Encephalitis Virus, Supplementary Figure 1), with lower rates determined by the most recently developed test, a C6-based rapid ELISA, than by conventional ELISA or IFAT (57).

Some studies also reported PCR detection rates in dogs, ranging from $0.0 \%$ in asymptomatic dogs (100) to $60.0 \%$ in animals with clinical signs attributable to borreliosis (87). DNA of B. burgdorferi s.s., B. afzelii, B. valaisiana, and B. garinii was amplified in these cases $(87,88)$.

Three studies reported data on cats (one each from the Czech Republic and the United Kingdom, one based on cats from different European countries). Two of these assessed seroprevalence, which ranged from $2.2 \%$ in symptomatic cats from different European countries, determined by a C6-based rapid ELISA (101), to $19.2 \%$ of cats presented at veterinary clinics in the Czech Republic, determined by conventional ELISA (102). The third study determined a $1.6 \%$ B. burgdorferi s.l. infection rate in systemically ill cats in the United Kingdom by PCR (103).

\section{Borrelia miyamotoi}

Borrelia miyamotoi was first isolated from Ixodes persulcatus in Japan in 1995 (19), but pathogenicity for humans was not recognized until 2011 (20). Since then, this pathogen has been known to cause a febrile illness (104) and, more recently, it has been associated with meningoencephalitis in immunocompromised patients $(105,106)$. Similar to $B$. burgdorferi s.l., rodents and birds seem to be reservoir hosts for this spirochaete (104). Little is known about the role of domestic animals regarding B. miyamotoi ecology. In contrast to $B$. burgdorferi s.l., prevalence of $B$. miyamotoi in ticks is not negatively affected by the presence of cattle $(62,107)$. Borrelia miyamotoi DNA has been detected in two healthy cats in the USA (108). However, infection of other domestic animals has not been documented so far to the authors' knowledge and no (sero-)prevalence studies have been conducted.

\section{Anaplasma phagocytophilum}

Anaplasma phagocytophilum is regarded as an important zoonotic pathogen, causing disease in humans, domestic ruminants, horses, dogs, and rarely in cats, while wild mammals act as reservoir hosts (109). This obligate intracellular rickettsial pathogen replicates in neutrophilic granulocytes and leads to thrombocytopenia, leukopenia, anemia, and immunosuppression associated with variable clinical signs (110). The epidemiology of A. phagocytophilum is complex due to the circulation of various strains and ecotypes, and shows considerable differences between Europe and North America (109). Human, equine, and canine granulocytic anaplasmosis have been described in Asia, Europe, and North America, while domestic ruminants only seem to be affected in Europe (109). Based on groEL genetic sequences, eight haplotype clusters of $A$. phagocytophilum were recently identified, and most isolates from humans and domestic animals belong to cluster 1, while other clusters, e.g., containing samples from roe deer, do not seem to be zoonotic (111).

Overall, 65 studies reporting (sero-)prevalence rates of $A$. phagocytophilum in domestic animals in the study region were retrieved (Supplementary Table 3). The meta-analysis based on seroprevalence rates of asymptomatic animals, including data 
on 35 animal cohorts (2x cattle, $3 \mathrm{x}$ sheep, 9x horses, $18 \mathrm{x}$ dogs, $3 \mathrm{x}$ cats) from 28 publications, yielded an estimated overall seroprevalence of $16.2 \%$ (95\% CI: 11.7-22.0\%), with a significant level of heterogeneity ( $I^{2}=98.6 \%$; 95\% CI: 98.4-98.8\%; $P<$ 0.001). Although rather high seroprevalence rates were detected in sheep as compared to the other animal species, subgroup analyses indicated no significant difference (test for subgroup differences: $\chi^{2}=6.4, \mathrm{df}=4, P=0.171$; Figure 6). Likewise, significant differences according to geographical region $\left(\chi^{2}=\right.$ 0.38 , df $=2, P=0.828)$, the decades of sampling $\left(\chi^{2}=0.78\right.$, $\mathrm{df}=2, P=0.676$; Figure 6) or the type of diagnostic test were not detected $\left(\chi^{2}=4.98, \mathrm{df}=2, P=0.083\right)$.

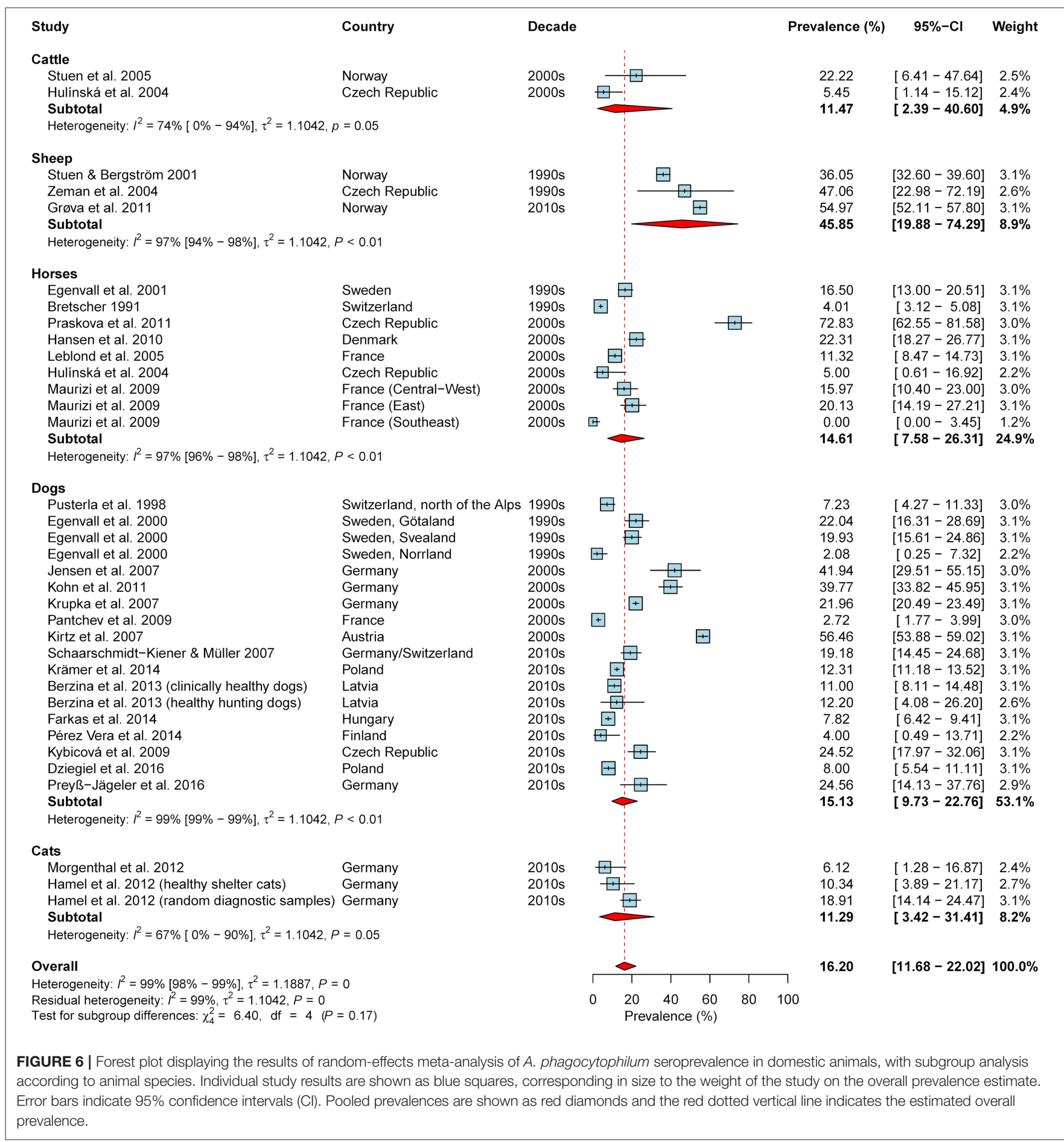




\section{Ruminants}

In domestic ruminants, the disease caused by A. phagocytophilum is known as tick-borne fever and presents with fever, anorexia, abortion and a drop in milk production (109). In sheep but not in cattle, immunosuppression is also common, frequently resulting in secondary infections (112), which may be fatal in some cases (113). After recovery, sheep develop persistent infections with recurrent phases of high bacteraemia for at least 1 year, suggesting they may also act as a pathogen reservoir $(114,115)$. Furthermore, field data suggest that cattle can also become persistently infected or are frequently re-infected, indicating a possible reservoir function, which needs to be explored further (116). Recent genetic analyses have shown that A. phagocytophilum isolates from sheep and cattle in Europe cluster with isolates from humans, dogs, and horses (117).

In total, six studies reported (sero-)prevalence rates for cattle (two studies from Sweden and one study each from Belgium, the Czech Republic, Norway, and Switzerland), seven for sheep (two each from the Czech Republic and Norway, one each from Denmark, Germany and Sweden), and two for goats (Switzerland and United Kingdom, Supplementary Table 3).

In cattle, seroprevalence rates varied from $5.5 \%$ in the Czech Republic (118) to $100 \%$ in a clinically-affected herd in Norway (119). The highest published seroprevalence rate in asymptomatic cattle was $63.0 \%$ in a Swiss study (120). Three studies reported prevalence rates based on PCR, which ranged from $5.5 \%$ in the Czech Republic (118) to $85.7 \%$ in symptomatic animals in Sweden (121).

In sheep, prevalence of $A$. phagocytophilum antibodies ranged from $36.0 \%$ in Norway (122) to $100 \%$ in a flock in the Czech Republic (123). PCR-determined prevalence rates in sheep varied from $2.9 \%$ in the Czech Republic/Slovakia (124) to $41.9 \%$ in sheep flocks with high lamb morbidity and mortality in Sweden (43). Regarding goats, a PCR-determined prevalence of 5.6\% was reported from Switzerland (125). In addition, four of five feral goats caught in Northern Ireland, UK, were PCR-positive (126).

However, (sero-)prevalence rates in ruminants may be difficult to compare between studies, since marked seasonal variation has been found. For example, in a Swiss study, seroprevalence of two cattle herds varied between $16 \%$ before and $63 \%$ at the end of the grazing season (120). As most ruminants are housed during winter, determined (sero-)prevalence rates greatly depend upon the season of sampling.

In addition, serologic cross-reactivity with other Anaplasma spp., e.g., Anaplasma marginale in cattle (127) and probably also Anaplasma ovis in sheep (128), needs to be considered. In Europe, A. marginale occurs mainly in the Mediterranean region, but also in Switzerland, Austria, and Hungary (129). Anaplasma ovis has been detected in France (130) as well as Slovakia (124) and Hungary (129).

\section{Horses}

In horses, A. phagocytophilum may cause an acute febrile disease with depression, anorexia, ataxia, icterus, and lower limb oedema, which is usually self-limiting (131). Similar to sheep, horses may develop persistent subclinical infections with recurrent bacteraemia after spontaneous recovery from acute disease (132). Notably, equine A. phagocytophilum strains seem to be similar or identical to those causing disease in humans and dogs (133).

Most equine granulocytic anaplasmosis (EGA) cases have been reported from European countries (131). In the present investigation, 11 studies reporting (sero-)prevalence rates of A. phagocytophilum in horses were identified, two each from the Czech Republic, France, and Sweden and one each from Denmark, France, the Netherlands, Switzerland, and Sweden. Another two studies reported data from Poland, Slovakia and the Ukraine and from Germany, Poland and the Ukraine, respectively. Reported seroprevalence rates ranged from $4.0 \%$ in Switzerland (134) to $72.8 \%$ in the Czech Republic (135). Remarkably, the latter study was based on healthy horses. Prevalences determined by PCR ranged from $0.0 \%$ in the Ukraine (136) to $62.9 \%$ in Sweden, whereby the latter study was based on horses presenting symptoms attributable to EGA.

\section{Dogs and Cats}

Canine granulocytic anaplasmosis (CGA) is regarded as one of the most important vector-borne diseases in Europe. While many cases are probably subclinical, acute febrile illness may also occur (137). Frequent clinical signs are lethargy, anorexia, and pale mucous membranes, sometimes accompanied by enlarged lymph nodes, bleeding (petechias, epistaxis), and immune-mediated arthritis (137). Similar symptoms may be seen in cats infected with $A$. phagocytophilum, although experimental studies indicate that symptoms are usually mild (138). Experimental infections have been shown to persist for at least $5^{1 / 2}$ months in dogs (139) and 3 months in cats (91). The A. phagocytophilum strains causing disease in dogs seem to be zoonotic (117).

In total, 37 studies on A. phagocytophilum (sero-)prevalence in dogs were retrieved from the literature, including 10 from Germany, six from Poland, five from Sweden, two each from Austria, the Czech Republic, Hungary Slovakia, and Switzerland, and one study each from Finland, France, Latvia, Lithuania, and the United Kingdom. One study included dogs from Germany and Switzerland. Reported seroprevalence rates, determined either by IFAT or (rapid) ELISA, ranged from $2.1 \%$ in northern Norway (96) to 56.5\% in Austria (140) (Supplementary Table 3). However, the latter study included dogs with symptoms possibly related to CGA. Since infection may not lead to clinical disease, and CGA is characterized by rather unspecific symptoms, several studies did not find a significant difference in seroprevalence between apparently healthy animals and those presenting some form of illness [e.g., (100, 141)]. Nevertheless, cohorts of symptomatic dogs were excluded from the meta-analysis on seroprevalence. Serologic tests available for assessing A. phagocytophilum exposure may cross-react with Anaplasma platys antibodies, therefore, seroprevalence may be overestimated. However, as A. platys transmission in Europe is restricted to Mediterranean countries (137), this pathogen only plays a role as an imported bacterium in the countries considered in this review, with the exception of southern France. Nevertheless, with increased travel activity and import of dogs by animal welfare organizations, this should be kept in mind when interpreting seroprevalence rates. 
Prevalence rates determined by PCR ranged from $0.0 \%$ in Switzerland and Poland $(142,143)$ to $66.7 \%$ in dogs with symptoms attributable to CGA in Sweden (121). The highest prevalence in apparently healthy dogs was $12.2 \%$ in a group of Latvian hunting dogs (144).

Regarding cats, six studies were found (four from Germany, one from the United Kingdom and one from Ireland). These studies reported IFAT-determined seroprevalence rates from $6.1 \%$ in healthy cats (145) to $18.9 \%$ in random diagnostic samples (146). PCR detection rates varied from $0.0 \%$ in healthy cats (145) to $4.3 \%$ in necropsy samples from shelter cats (147).

\section{Neoehrlichia mikurensis}

Neoehrlichia mikurensis, a member of the family Anaplasmataceae, was first discovered in the early 2000s, recognized as a human pathogen in 2010 and recently cultivated in tick cell lines as well as human endothelial cells (148). It occurs in I. ricinus populations throughout Europe and human cases, mainly involving immunosuppressed patients, have been reported from several countries (149). Regarding domestic animals, knowledge on the relevance of $N$. mikurensis as a pathogenic agent and respective prevalence data are scarce.

In the present literature survey, five studies investigating $N$. mikurensis occurrence in domestic animals (four in dogs and one in cats) by PCR, but no seroprevalence studies, were obtained (Table 1). Infections in dogs seem to be rare, as only $0.3 \%$ of 1,023 dogs in Germany (151) and $0.1 \%$ of 889 dogs in Switzerland were infected (142). The positive dog in Switzerland was splenectomised (142). Another positive dog died of haemolytic anemia in the Czech Republic (150) and in a case report from Germany, canine N. mikurensis infection was associated with neutropenia and thrombocytopenia (23). However, the clinical relevance of N. mikurensis in dogs is still unclear $(23,142)$. A single study also tested spleen samples from 141 cats in Germany, but N. mikurensis was not detected (147). Other domestic animal species have not been investigated so far to the authors' knowledge.

\section{Rickettsia spp.}

Several tick-transmitted human-pathogenic Rickettsia spp. occur in Europe. While the causative agent of Mediterranean spotted fever, Rickettsia conorii, has been known since the beginning of the twentieth century, several further Rickettsia spp. and their associated syndromes were described in the 1990s and 2000s (153). In central and northern Europe, R. helvetica, transmitted by $I$. ricinus, is probably the most frequent species. It causes a mild febrile illness in humans and is only sometimes associated with skin rash (154). In addition, I. ricinus may transmit Rickettsia monacensis, which leads to a clinical picture similar to Mediterranean spotted fever (153). Rickettsia slovaca and $R$. raoultii, causative agents of scalp eschar and neck lymphadenopathy (SENLAT), are transmitted by Dermacentor species (153).

With the exception of dogs, domestic animals do not seem to be susceptible to disease caused by human-pathogenic Rickettsia species. In dogs, infection with Rickettsia rickettsii, which causes Rocky Mountain spotted fever in North America, leads to clinical signs similar to those in humans (155). In addition, $R$. conorii has been associated with canine febrile illness (156). Dogs are also capable of transmitting $R$. conorii to ticks and may thus exert a reservoir function (157). However, canine disease due to the Rickettsia spp. relevant in central and northern Europe or a respective reservoir function have not been reported to the authors' knowledge.

Overall, domestic animals can mainly be regarded as sentinels for human exposure to Rickettsia spp. in central and northern Europe. However, only nine studies were identified (three from Germany, two from Switzerland, one each from the Czech Republic, Ireland, Poland, and Sweden), reporting data on horses, dogs, and cats (Table 2). Regarding domestic ruminants, no studies on Rickettsia (sero-)prevalence in the considered geographical region were obtained. The only study on horses reported a $36.5 \% R$. helvetica seroprevalence in Sweden (158).

In dogs, a high level of exposure to spotted-fever group rickettsiae was reported, with seroprevalence rates ranging from 17.0 to $93.9 \%(158,160)$. When $R$. helvetica-specific antigens were used, seroprevalences of $17.0 \%$ (158) and 66.0\% (160) were determined. Despite this high level of exposure, Rickettsia DNA (mainly $R$. raoultii) was found in only $0.8 \%$ of tested dogs in Germany (151), whereas two PCR-based studies from Switzerland $(142,162)$ and one study from Poland (161) reported

TABLE 1 | (Sero-)prevalence studies on Neoehrlichia mikurensis in domestic animals in temperate and cold regions of Europe.

\begin{tabular}{|c|c|c|c|c|c|c|c|}
\hline Country & Region & Year(s) of sampling & Method(s) & Positive/total & Prevalence & Comment(s) & References \\
\hline \multicolumn{8}{|l|}{ DOGS } \\
\hline Czech Republic & NA & 2009-2012 & PCR & $1 / 19$ & $5.3 \%$ & $\begin{array}{l}\text { Dogs with fatal immunhaemolytic } \\
\text { anemia }\end{array}$ & $(150)$ \\
\hline Germany & Brandenburg & 2013-2014 & HRM PCR & $3 / 1,023$ & $0.3 \%$ & & $(151)$ \\
\hline Hungary & Somogy & NA & PCR & $0 / 90$ & $0.0 \%$ & $\begin{array}{l}\text { Candidatus Neoehrlichia lotoris-like } \\
\text { detected in } 6 \text { dogs }\end{array}$ & $(152)$ \\
\hline Switzerland & Zurich & 2005-2006 & Real-time PCR & $1 / 889$ & $0.1 \%$ & The positive dog was splenectomised & $(142)$ \\
\hline \multicolumn{8}{|l|}{ CATS } \\
\hline Germany & Berlin & 2006-2008 & HRM PCR & $0 / 141$ & $0.0 \%$ & Spleen samples from shelter cats & $(147)$ \\
\hline
\end{tabular}

HRM PCR, high-resolution melt PCR. 
TABLE 2 | (Sero-)prevalence studies on tick-transmitted Rickettsia spp. in domestic animals in temperate and cold regions of Europe.

\begin{tabular}{|c|c|c|c|c|c|c|c|}
\hline Country & Region & Year(s) of sampling & Method(s) & Positive/total & Prevalence & Comment(s) & References \\
\hline \multicolumn{8}{|l|}{ HORSES } \\
\hline Sweden & NA & 2010-2011 & IFAT & 23/63 & $36.5 \%$ & R. helvetica used as antigen & $(158)$ \\
\hline \multicolumn{8}{|l|}{ DOGS } \\
\hline Czech Republic & NA & 2009-2012 & PCR & $0 / 19$ & $0.0 \%$ & $\begin{array}{l}\text { Dogs with fatal immunhaemolytic } \\
\text { anemia }\end{array}$ & $(150)$ \\
\hline \multirow[t]{3}{*}{ Germany } & Nationwide & 2012-2014 & ELISA $^{a}$ & $469 / 602$ & $77.9 \%$ & Dogs that never left Germany & $(159)$ \\
\hline & Nationwide & 2012-2014 & Micro-IFAT & $568 / 605$ & $93.9 \%$ & $\begin{array}{l}\text { Same samples as in (159); } \\
\text { clearly differentiable samples: } \\
66.0 \% \text { R. helvetica, } 2.8 \% R \text {. } \\
\text { raoultii, } 1.6 \% \text { R. slovaca }\end{array}$ & $(160)$ \\
\hline & Brandenburg & 2013-2014 & PCR & $8 / 1,021$ & $0.8 \%$ & $\begin{array}{l}\text { Identified species: } 7 \times R \text {. raoultii, } \\
1 \times R . \text { felis }\end{array}$ & $(151)$ \\
\hline Poland & $\begin{array}{l}\text { North-Western } \\
\text { Poland }\end{array}$ & NA & PCR & $\begin{array}{l}\text { 0/100 (group 1), } \\
\text { 0/92 (group 2), } \\
\text { 0/50 (group 3) }\end{array}$ & $\begin{array}{l}0.0 \% \text { (group } 1) \\
0.0 \% \text { (group } 2) \\
0.0 \% \text { (group } 3)\end{array}$ & $\begin{array}{l}\text { Group 1: healthy shelter dogs, } \\
\text { group 2: suspected borreliosis, } \\
\text { group 3: diagnosed babesiosis }\end{array}$ & $(161)$ \\
\hline Sweden & NA & 2010-2011 & IFAT & $17 / 100$ & $17.0 \%$ & R. helvetica used as antigen & $(158)$ \\
\hline \multirow[t]{2}{*}{ Switzerland } & Zurich & 2005-2006 & Real-time PCR ${ }^{\mathrm{b}}$ & 0/889 & $0.0 \%$ & & $(142)$ \\
\hline & Zurich & NA & Real-time PCR ${ }^{\mathrm{b}}$ & 0/884 & $0.0 \%$ & & $(162)$ \\
\hline \multicolumn{8}{|l|}{ CATS } \\
\hline Ireland & Dublin & 2008 & PCR & $0 / 121$ & $0.0 \%$ & & $(163)$ \\
\hline Sweden & NA & 2010-2011 & IFAT & 19/90 & $22.1 \%$ & R. helvetica used as antigen & $(158)$ \\
\hline
\end{tabular}

${ }^{a}$ Commercially available, detects all spotted-fever group rickettsiae.

${ }^{b}$ Specific for $R$. helvetica.

ELISA, enzyme-linked immunosorbent assay; IFAT, immunofluorescence antibody test.

$0.0 \%$ prevalence. Similarly, $R$. helvetica antibodies were detected in $22.1 \%$ of tested cats in Sweden (158), but no Rickettsia DNA was amplified from 121 tested cats in Ireland (163). Therefore, it seems unlikely that dogs and cats contribute to the epidemiology of tick-transmitted rickettsioses as reservoir hosts in northern and central Europe.

\section{Zoonotic Babesia spp.}

Piroplasms of the genus Babesia are tick-transmitted protozoan parasites, which usually display a high degree of host specificity. Nevertheless, a few species are zoonotic, predominantly affecting immunocompromised patients (24). In Europe, most human infections are caused by the cattle parasite $B$. divergens (154). On the American continent, human babesiosis due to Babesia microti, which is rodent-associated, is more common. Babesia microti also occurs in Europe. However, clinically symptomatic human B. microti infections reported in Europe were mostly acquired in the Americas, so it is unclear whether European B. microti strains are human-pathogenic (154). Furthermore, Babesia venatorum, a parasite of deer, has been recognized as a human pathogen in immunocompromised patients in Europe (154).

Regarding domestic animals, only cattle are affected by and act as reservoirs for a Babesia spp. with zoonotic relevance, namely $B$. divergens, whereas the species parasitizing horses, sheep, goats, and dogs are not zoonotic. No cat-specific Babesia species are distributed in Europe. Babesia microti DNA has been detected in cats in southern Europe (e.g., in Italy) but the relevance of this finding remains unclear (164).
In cattle, $B$. divergens infection may lead to severe haemolytic anemia, which can be fatal $(165,166)$. Symptoms consist of fever, pale or jaundiced mucous membranes, anorexia, weakness, elevated heart and respiratory rates and hemoglobinuria, hence the colloquial name of the disease, "redwater" (165). Recovering animals acquire immunity, which is maintained by repeated pathogen exposure (165). Calves under the age of $\sim 9$ months display higher resistance toward clinical disease and are subsequently immunologically protected $(167,168)$, thus, clinical disease in endemic situations usually only occurs in immunologically naïve animals, which were either recently introduced to the area or had no access to pasture during the first year of life (165).

In the present survey, 18 studies reporting Babesia (sero-)prevalence data in cattle were retrieved (four each from France, Germany, and the United Kingdom, two from Belgium, and one each from Hungary, Norway, Sweden, and Switzerland; Table 3). Reported seroprevalence rates, determined mostly by IFAT, ranged from $0.0 \%$ in asymptomatic animals in Northern Germany (177) to $100 \%$ in animals presenting with acute babesiosis in France (172). The highest seroprevalence in randomly chosen individuals, but from a region where babesiosis was known to occur, was $90.6 \%$ at the end of the grazing season (167). The latter study also showed that seroprevalence varied throughout the year, similar to the pattern described above for A. phagocytophilum (120), making different studies difficult to compare. Keeping this draw-back in mind, an overall seroprevalence of $7.4 \%$ (95\% CI: $2.6-$ $19.2 \%$ ) was estimated based on 11 healthy or randomly chosen 
TABLE 3 | (Sero-)prevalence studies on zoonotic Babesia spp. in domestic animals in temperate and cold regions of Europe.

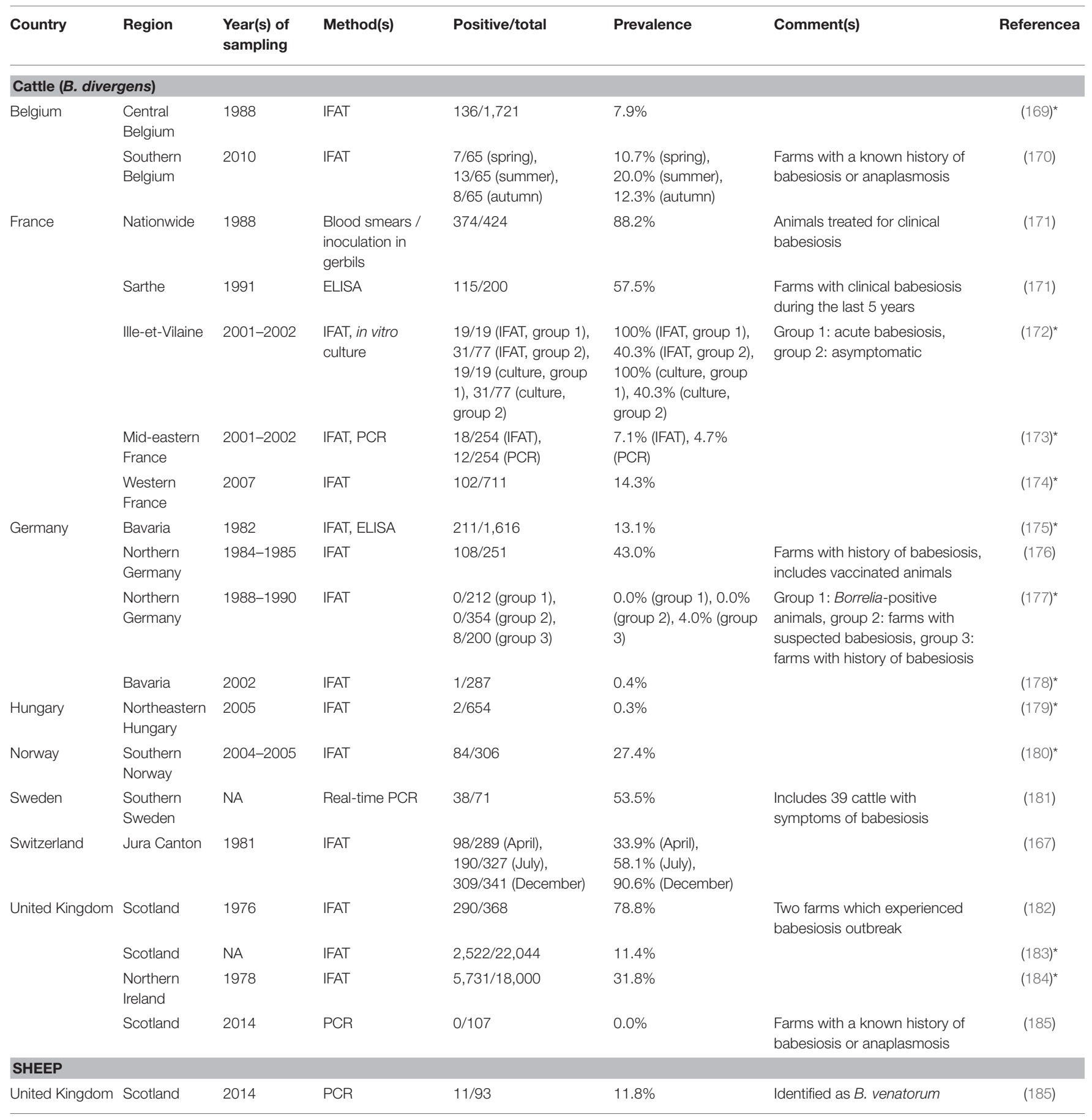

*Included in meta-analysis of seroprevalence.

ELISA, enzyme-linked immunosorbent assay, IFAT, immunfluorescence antibody test.

cattle cohorts (Supplementary Figure 2). A significant level of heterogeneity was detected $\left(I^{2}=99.6 \%\right.$; $95 \%$ CI: $99.6-99.7 \%$; $P<0.001)$. No significant temporal change in seroprevalence was detected from the 1970s to the 2000s (test for subgroup differences, $\left.\chi^{2}=0.96, \mathrm{df}=2, P=0.619\right)$, although a decline in bovine babesiosis prevalence and/or clinical incidence has been postulated for several European countries (179, 180, 186). This may be due to the fact that several studies reporting this decline were based on clinical incidence $(179,186)$ and were thus not included in the calculation. Furthermore, no difference according to geographical region was found $\left(\chi^{2}=5.8\right.$, $\mathrm{df}=3, P=0.121)$. 
A few studies also reported detection of $B$. divergens by PCR, with infection rates ranging from $0.0 \%$ in Scotland (185) to $53.5 \%$ among clinically symptomatic cattle in Sweden (181). In randomly selected cattle in France, an infection rate of $4.7 \%$ was determined by PCR (173).

In addition to cattle, sheep might act as reservoirs for zoonotic Babesia spp., as $B$. venatorum infections have recently been detected in $11.8 \%$ of 93 studied sheep in the United Kingdom, whereas the 107 tested cattle were negative (185).

\section{DISCUSSION}

The present survey aimed at presenting an overview of the most important zoonotic TBDs in domestic animals in temperate and cold regions of Europe, where $I$. ricinus is the predominant tick vector. While a rather large number of studies on $B$. burgdorferi s.l., A. phagocytophilum and TBEV were retrieved, studies on Rickettsia spp. in domestic animals were few, probably because Rickettsia spp. have not (yet) been associated with clinical disease in these species. Therefore, the prevalence and clinical relevance of Rickettsia spp. in domestic animals represent a knowledge gap. Similarly, only few studies exist on the relatively recently discovered pathogen N. mikurensis in domestic animals, although first reports indicate that this pathogen may be of clinical relevance for dogs (150). Studies on relevant zoonotic Babesia spp. were only found with regard to $B$. divergens in cattle, while only one study investigated $B$. venatorum, which is usually deer-associated, in cattle and sheep. As Babesia spp. are characterized by a high level of host-specificity (187), it was not surprising that no prevalence studies were conducted on rodent-associated $B$. microti in domestic animals in the considered regions.

In general, a high level of heterogeneity was detected in the datasets. To limit this heterogeneity in meta-analysis of seroprevalence, only animal cohorts asymptomatic for the considered pathogen or random diagnostic samples were included, and further restrictions were applied regarding the diagnostic test used for TBEV in all domestic animals and $B$. burgdorferi s.l. in dogs. Nevertheless, heterogeneity remained high, even after conducting subgroup analyses according to species, diagnostic test (if applicable), geographic region and decade. A significant effect was only found regarding species differences in B. burgdorferi s.l. infections, with higher rates in domestic ruminants and horses than in dogs. On the one hand, this might be due to the close relationship between dogs and their owners, resulting in better protection from TBDs due to treatment with (repellent) acaricides, and shorter duration of tick attachment, as ticks are probably noticed sooner on dogs than on horses or cattle. On the other hand, the choice of diagnostic test may have contributed to the significantly lower B. burgdorferi s.l. seroprevalence in dogs. Although no significant effect of diagnostic test was found in the overall dataset, analyzing the data subset on dogs alone revealed a significant effect, with lower rates determined by the most recently developed test, a rapid ELISA with a high sensitivity and specificity for antibodies against the Borrelia C6 antigen (57). This test was almost exclusively used in dogs, except for two studies on horses. This indicates that crossreactivity with other pathogens, e.g., Leptospira spp. (74), may have been an issue, especially in older and in non-canine studies.

Regarding A. phagocytophilum, conspicuously high seroprevalence rates in sheep were reported. However, as the meta-analysis included only three studies on sheep, no significant species differences were found when conducting subgroup analysis. However, this should be investigated further, as granulocytic anaplasmosis is a severe, possibly fatal disease in sheep (113). In addition, sheep might constitute a reservoir for human-pathogenic $A$. phagocytophilum strains (114, 115, 117). Thus, more studies on A. phagocytophilum (sero-)prevalence in sheep seem warranted.

In addition to species differences and different diagnostic tests used, the chosen cut-off level to determine seropositivity, the source of the antigen in serological tests or the timing of sampling-as seroprevalences may increase during seasons of tick exposure $(120,171)$-may have further increased heterogeneity of study results. These aspects, hampering the comparability of studies, may have contributed to the fact that no temporal changes in TBD seroprevalence in domestic animals were found. Possibly, a larger number of studies may have been necessary to detect a temporal trend under these conditions. Furthermore, there were large temporal gaps in the available seroprevalence studies. For example, studies on TBEV considered suitable for meta-analysis were mainly conducted as of the year 2000, with only one comparable study from the 1960s and none from the decades in between. Regarding Babesia spp., there was a gap in available screening studies on asymptomatic animals concerning the 1990s as well as the 2010s. Regarding B. burgdorferi s.l., most studies were conducted in the 1980s, following the initial description of the pathogen (188).

In consequence, the trend of increasing TBD incidence in humans was not reflected by the available data from domestic animals. Apart from the mentioned drawbacks that may have masked such a trend, it is also possible that seroprevalences in domestic animals are rather stable and that the increased TBD incidence in humans is due to factors which are not relevant for animals. For example, increased exposure due to more outdoor activities or increased awareness of patients and physicians for TBDs may lead to an increased disease incidence or more diagnoses of TBD infections in humans (2).

With regard to the geographical spread of zoonotic TBDs, e.g., concerning TBE, (sero-)prevalence in animals is usually not studied in a certain area until there is an indication of pathogen presence due to human cases. Therefore, it is difficult to ascertain when the pathogen emerged in animal populations in this area. As an example, no studies on TBEV in domestic animals in the United Kingdom were retrieved, where TBEV has only recently been detected (17).

\section{CONCLUSIONS}

This survey revealed a high heterogeneity in (sero-)prevalences of zoonotic TBDs in domestic animals in temperate and cold regions of Europe. In addition, temporal gaps in available 
studies were detected, e.g., for TBEV and $B$. divergens. The high level of heterogeneity as well as the temporal gaps make it difficult to assess long-term temporal trends for comparison with data on humans. Furthermore, only few studies were retrieved regarding Rickettsia spp. and the recently described pathogen $N$. mikurensis, and none regarding B. miyamotoi. Therefore, more studies investigating these neglected pathogens are warranted. Additionally, further surveillance studies employing highly sensitive and specific test methods and including hitherto noninvestigated regions are needed to determine if and how a changing world impacts the frequency of neglected zoonotic tick-borne pathogens in domestic animals.

\section{AUTHOR CONTRIBUTIONS}

CS designed the study. AS, AG, and A-KT conducted the literature search. AS conducted statistical analyses and

\section{REFERENCES}

1. WHO/FAO. Joint FAO/WHO Expert Committee on Zoonoses [Meeting Held in Geneva from 6 to 12 December 1966]: Third Report.World Health Organization, Geneva (1967).

2. Vayssier-Taussat M, Cosson JF, Degeilh B, Eloit M, Fontanet A, Moutailler $\mathrm{S}$, et al. How a multidisciplinary 'One health' approach can combat the tick-borne pathogen threat in Europe. Future Microbiol. (2015) 10:80918. doi: $10.2217 / \mathrm{fmb} .15 .15$

3. Rubel F, Brugger K, Pfeffer M, Chitimia-Dobler L, Didyk YM, Leverenz $\mathrm{S}$, et al. Geographical distribution of Dermacentor marginatus and Dermacentor reticulatus in Europe. Ticks Tick Borne Dis. (2016) 7:22433. doi: 10.1016/j.ttbdis.2015.10.015

4. Ličková M, Fumačová Havlíková S, Sláviková M, Slovák M, Drexler JF, Klempa B. Dermacentor reticulatus is a vector of tick-borne encephalitis virus. Ticks Tick Borne Dis. (2020) 11:101414. doi: 10.1016/j.ttbdis.202 0.101414

5. Hvidsten D, Frafjord K, Gray JS, Henningsson AJ, Jenkins A, Kristiansen BE, et al. The distribution limit of the common tick, Ixodes ricinus, and some associated pathogens in north-western Europe. Ticks Tick Borne Dis. (2020) 11:101388. doi: 10.1016/j.ttbdis.2020.101388

6. Jore S, Vanwambeke SO, Viljugrein $H$, Isaksen $K$, Kristoffersen AB, Woldehiwet $\mathrm{Z}$, et al. Climate and environmental change drives Ixodes ricinus geographical expansion at the northern range margin. Parasit Vectors. (2014) 7:11. doi: 10.1186/1756-3305-7-11

7. Materna J, Daniel M, Metelka L, Harčarik J. The vertical distribution, density and the development of the tick Ixodes ricinus in mountain areas influenced by climate changes (The Krkonoše Mts., Czech Republic). Int J Med Microbiol. (2008) 298:25-37. doi: 10.1016/j.ijmm.2008.05.004

8. Mierzejewska EJ, Estrada-Peña A, Alsarraf M, Kowalec M, Bajer A. Mapping of Dermacentor reticulatus expansion in Poland in 2012-2014. Ticks Tick Borne Dis. (2016) 7:94-106. doi: 10.1016/j.ttbdis.2015.09.003

9. Dautel H, Dippel C, Oehme R, Hartelt K, Schettler E. Evidence for an increased geographical distribution of Dermacentor reticulatus in Germany and detection of Rickettsia sp. RpA4. Int J Med Microbiol. (2006) 296:14956. doi: 10.1016/j.ijmm.2006.01.013

10. Paulauskas A, Radzijevskaja J, Mardosaite-Busaitiene D, Aleksandravičiene A, Galdikas M, Krikštolaitis R. New localities of Dermacentor reticulatus ticks in the baltic countries. Ticks Tick Borne Dis. (2015) 6:6305. doi: 10.1016/j.ttbdis.2015.05.007

11. Drehmann M, Springer A, Lindau A, Fachet K, Mai S, Thoma D, et al. The spatial distribution of Dermacentor ticks (Ixodidae) in Germany - evidence of a continuing spread of Dermacentor reticulatus. Front Vet Sci. (2020) 7:578220. doi: 10.3389/fvets.2020.578220 drafted the manuscript. All authors participated in data interpretation, reviewed the manuscript draft, read, and approved the final manuscript.

\section{FUNDING}

This study was supported by a grant of the European Union through the European Regional Development Fund and the Interreg North Sea Region Programme 2014-2020 as part of the NorthTick project (reference number J-No: 38-2-7-19).

\section{SUPPLEMENTARY MATERIAL}

The Supplementary Material for this article can be found online at: https://www.frontiersin.org/articles/10.3389/fvets. 2020.604910/full\#supplementary-material
12. Sykes RA, Makiello P. An estimate of lyme borreliosis incidence in Western Europe. J Public Health. (2017) 39:74-81. doi: 10.1093/pubmed/fdw017

13. Hofhuis A, van der Giessen JW, Borgsteede F, Wielinga PR, Notermans DW, van Pelt W. Lyme borreliosis in the Netherlands: strong increase in GP consultations and hospital admissions in past 10 years. Eurosurveillance. (2006) 11:2978. doi: 10.2807/esw.11.25.02978-en

14. Tulloch JSP, Christley RM, Radford AD, Warner JC, Beadsworth MBJ, Beeching NJ, et al. A descriptive epidemiological study of the incidence of newly diagnosed lyme disease cases in a UK primary care cohort, 1998-2016. BMC Infect Dis. (2020) 20:285. doi: 10.1186/s12879-020-05018-2

15. Süss J. Tick-borne encephalitis in Europe and beyond - the epidemiological situation as of 2007. Eurosurveillance. (2008) 13:18916. doi: 10.2807/ese.13.26.18916-en

16. Dekker M, Laverman GD, de Vries A, Reimerink J, Geeraedts F. Emergence of tick-borne encephalitis (TBE) in the Netherlands. Ticks Tick Borne Dis. (2019) 10:176-9. doi: 10.1016/j.ttbdis.2018.10.008

17. Holding M, Dowall SD, Medlock JM, Carter DP, Pullan ST, Lewis J, et al. Tick-borne encephalitis virus, United Kingdom. Emerg Infect Dis. (2020) 26:90-6. doi: 10.3201/eid2601.191085

18. Kernif T, Leulmi H, Raoult D, Parola P. Emerging tick-borne bacterial pathogens. In: Scheld WM, Hughes JM, Whitley RJ, editors. Emerging Infections. Washington, DC: American Society for Microbiology (2016). p. 295-310.

19. Fukunaga M, Takahashi Y, Tsuruta Y, Matsushita O, Ralph D, Mcclelland $\mathrm{M}$, et al. Genetic and phenotypic analysis of Borrelia miyamotoi sp. nov., isolated from the ixodid tick Ixodes persulcatus, the vector for Lyme Disease in Japan. Int J Syst Evol Microbiol. (1995) 45:804-10. doi: 10.1099/0020771345-4-804

20. Platonov AE, Karan LS, Kolyasnikova NM, Makhneva NA, Toporkova MG, Maleev VV, et al. Humans infected with relapsing fever spirochete Borrelia miyamotoi, Russia. Emerg Infect Dis. (2011) 17:1816-23. doi: 10.3201/eid1710.101474

21. Kawahara M, Rikihisa Y, Isogai E, Takahashi M, Misumi H, Suto C, et al. Ultrastructure and phylogenetic analysis of 'Candidatus Neoehrlichia mikurensis' in the family Anaplasmataceae, isolated from wild rats and found in Ixodes ovatus ticks. Int J Syst Evol Microbiol. (2004) 54:183743. doi: 10.1099/ijs.0.63260-0

22. Welinder-Olsson $\mathrm{C}$, Kjellin $\mathrm{E}$, Vaht $\mathrm{K}$, Jacobsson $\mathrm{S}$, Wennerås C. First case of human "Candidatus Neoehrlichia mikurensis" infection in a febrile patient with chronic lymphocytic leukemia. J Clin Microbiol. (2010) 48:19569. doi: 10.1128/JCM.02423-09

23. Diniz PPVP, Schulz BS, Hartmann K, Breitschwerdt EB. "Candidatus Neoehrlichia mikurensis” infection in a dog from Germany. J Clin Microbiol. (2011) 49:2059-62. doi: 10.1128/JCM.02327-10 
24. Gray J, Zintl A, Hildebrandt A, Hunfeld K-P, Weiss L. Zoonotic babesiosis: overview of the disease and novel aspects of pathogen identity. Ticks Tick Borne Dis. (2010) 1:3-10. doi: 10.1016/j.ttbdis.2009.11.003

25. Dobler G, Gniel D, Petermann R, Pfeffer M. Epidemiology and distribution of tick-borne encephalitis. Wien Med Wochenschr. (2012) 162:2308. doi: 10.1007/s10354-012-0100-5

26. Schwarzer G. meta: an R package for meta-analysis. $R$ News. (2007) 7:40-5.

27. R Core Team. R: A Language and Environment for Statistical Computing. 3.5.0 ed. Vienna: R Foundation for Statistical Computing (2018).

28. Maulik PK, Mascarenhas MN, Mathers CD, Dua T, Saxena S. Prevalence of intellectual disability: a meta-analysis of population-based studies. Res Dev Disabil. (2011) 32:419-36. doi: 10.1016/j.ridd.2010.12.018

29. Dobler G, Hufert F, Pfeffer M, Essbauer S. Tick-borne encephalitis: from microfocus to human disease. In: Mehlhorn $\mathrm{H}$, editor. Progress in Parasitology. Berlin: Springer. (2011) p. 323-31. doi: 10.1007/978-3-642-21396-0_17

30. Imhoff M, Hagedorn P, Schulze Y, Hellenbrand W, Pfeffer M, Niedrig M. Review: sentinels of tick-borne encephalitis risk. Ticks Tick Borne Dis. (2015) 6:592-600. doi: 10.1016/j.ttbdis.2015.05.001

31. Roelandt S, Suin V, Gucht S, Stede Y, Roels S. Comparative tick-borne encephalitis (virus) surveillance in Belgium 2009-2015: experiences with diagnostic tests, sentinel species and surveillance designs. J Zoonotic Dis Public Health. (2017) 1:4.

32. Paulsen KM, Granquist EG, Okstad W, Vikse R, Stiasny K, Andreassen $\AA ̊ K$, et al. Experimental infection of lambs with tick-borne encephalitis virus and co-infection with Anaplasma phagocytophilum. PLoS ONE. (2019) 14:e0226836. doi: 10.1371/journal.pone.0226836

33. Balogh Z, Egyed L, Ferenczi E, Bán E, Szomor KN, Takács M, et al. Experimental infection of goats with tick-borne encephalitis virus and the possibilities to prevent virus transmission by raw goat milk. Intervirology. (2012) 55:194-200. doi: 10.1159/000324023

34. Balogh Z, Ferenczi E, Szeles K, Stefanoff P, Gut W, Szomor KN, et al. Tickborne encephalitis outbreak in hungary due to consumption of raw goat milk. J Virol Methods. (2010) 163:481-5. doi: 10.1016/j.jviromet.2009.10.003

35. Brockmann S, Oehme R, Buckenmaier T, Beer M, Jeffery-Smith A, Spannenkrebs $M$, et al. A cluster of two human cases of tick-borne encephalitis (TBE) transmitted by unpasteurised goat milk and cheese in Germany, May 2016. Eurosurveillance. (2018) 23:17-00336. doi: 10.2807/1560-7917.ES.2018.23.15.17-00336

36. Böhm B, Schade B, Bauer B, Hoffmann B, Hoffmann D, Ziegler U, et al. Tick-borne encephalitis in a naturally infected sheep. BMC Vet Res. (2017) 13:267. doi: 10.1186/s12917-017-1192-3

37. Zindel W, Wyler R. Zeckenenzephalitis bei einer Ziege im untern Prättigau. Schweiz Arch Tierheilkd. (1983) 125:383-6.

38. Klaus C, Ziegler U, Kalthoff D, Hoffmann B, Beer M. Tick-borne encephalitis virus (TBEV) - findings on cross reactivity and longevity of TBEV antibodies in animal sera. BMC Vet Res. (2014) 10:78. doi: 10.1186/1746-6148-10-78

39. van der Poel WHM, van der Heide R, Bakker D, Looff MD, Jong JD, van Manen N, et al. Attempt to detect evidence for tick-borne encephalitis virus in ticks and mammalian wildlife in the Netherlands. Vector Borne Zoonotic Dis. (2005) 5:58-64. doi: 10.1089/vbz.2005.5.58

40. Šikutová S, Hornok S, Hubálek Z, DoleŽálková I, Juricová Z, Rudolf I. Serological survey of domestic animals for tick-borne encephalitis and Bhanja viruses in northeastern Hungary. Vet Microbiol. (2009) 135:26771. doi: 10.1016/j.vetmic.2008.09.082

41. Paulsen KM, Stuen S, das Neves CG, Suhel F, Gurung D, Soleng A, et al. Tickborne encephalitis virus in cows and unpasteurized cow milk from Norway. Zoonoses Public Health. (2019) 66:216-22. doi: 10.1111/zph.12554

42. Klaus C, Beer M, Saier R, Schau U, Moog U, Hoffmann B, et al. Goats and sheep as sentinels for tick-borne encephalitis (TBE) virus - epidemiological studies in areas endemic and non-endemic for TBE virus in Germany. Ticks Tick Borne Dis. (2012) 3:27-37. doi: 10.1016/j.ttbdis.2011.09.011

43. Grandi G, Aspán A, Pihl J, Gustafsson K, Engström F, Jinnerot T, et al. Detection of tick-borne pathogens in lambs undergoing prophylactic treatment against ticks on two Swedish farms. Front Vet Sci. (2018) 5:6. doi: 10.3389/fvets.2018.00072

44. Gao GF, Jiang WR, Hussain MH, Venugopal K, Gritsun TS, Reid $\mathrm{HW}$, et al. Sequencing and antigenic studies of a Norwegian virus isolated from encephalomyelitic sheep confirm the existence of louping ill virus outside Great Britain and Ireland. J Gen Virol. (1993) 74:10914. doi: 10.1099/0022-1317-74-1-109

45. Frimmel S, Löbermann M, Feldhusen F, Seelmann M, Stiasny K, Süss J, et al. Detection of tick-borne encephalitis virus antibodies in sera of sheep and goats in Mecklenburg-Western Pomerania (north-eastern Germany). Ticks Tick Borne Dis. (2019) 10:901-4. doi: 10.1016/j.ttbdis.2019.04.012

46. Casati Pagani S, Frigerio Malossa S, Klaus C, Hoffmann D, Beretta O, Bomio-Pacciorini N, et al. First detection of TBE virus in ticks and sero-reactivity in goats in a non-endemic region in the southern part of Switzerland (Canton of Ticino). Ticks Tick Borne Dis. (2019) 10:86874. doi: 10.1016/j.ttbdis.2019.04.006

47. Salat J, Ruzek D. Tick-borne encephalitis in domestic animals. Acta Virol. (2020) 64:226-32. doi: 10.4149/av_2020_212

48. Waldvogel A, Matile H, Wegmann C, Wyler R, Kunz C. Tick-borne encephalitis in the horse. Schweiz Arch Tierheilkd. (1981) 123:227-33.

49. Klaus C, Hörügel U, Hoffmann B, Beer M. Tick-borne encephalitis virus (TBEV) infection in horses: clinical and laboratory findings and epidemiological investigations. Vet Microbiol. (2013) 163:368-72. doi: 10.1016/j.vetmic.2012.12.041

50. Pfeffer M, Dobler G. Tick-borne encephalitis virus in dogs - is this an issue? Parasit Vectors. (2011) 4:59. doi: 10.1186/1756-3305-4-59

51. Reiner B, Grasmück S, Steffen F, Djuric N, Schindler T, Müller W, et al. Prevalence of TBE antibodies in serum and CSF of dogs with inflammatory and non-inflammatory CNS disease. Int J Med Microbiol. (2002) 291(Suppl). 33:234. doi: 10.1016/S1438-4221(02)80069-8

52. Hekrlová A, Kubíček O, Lány P, Rosenbergová K, Schánilec P. Tick-borne encephalitis in dogs: application of "nested real-time RT-PCR" for intravital virus detection. Berl Munch Tierarztl Wochenschr. (2015) 128:397-401. doi: 10.23767/0005-9366-128-397

53. Margos G, Fedorova N, Becker NS, Kleinjan JE, Marosevic D, Krebs S, et al. Borrelia maritima sp. nov., a novel species of the Borrelia burgdorferi sensu lato complex, occupying a basal position to North American species. Int J Syst Evol Microbiol. (2020) 70:849-56. doi: 10.1099/ijsem.0.003833

54. Strnad M, Hönig V, Ružek D, Grubhoffer L, Rego ROM. Europewide meta-analysis of Borrelia burgdorferi sensu lato prevalence in questing Ixodes ricinus ticks. Appl Environ Microbiol. (2017) 83:e0060917. doi: 10.1128/AEM.00609-17

55. Strle F, Stanek G, Strle K. Lyme borreliosis: the European perspective. In: Halperin JJ, editor. Lyme Disease: An Evidence-based Approach. 2 ed. Wallingford; Oxfordshire; Boston, MA: CAB International (2018). p. 105-23.

56. Tufts DM, Hart TM, Chen GF, Kolokotronis S-O, Diuk-Wasser MA, Lin Y-P. Outer surface protein polymorphisms linked to hostspirochete association in Lyme borreliae. Mol Microbiol. (2019) 111:868-82. doi: 10.1111/mmi.14209

57. Pantchev N, Pluta S, Huisinga E, Nather S, Scheufelen M, Vrhovec MG, et al. Tick-borne diseases (borreliosis, anaplasmosis, babesiosis) in German and Austrian dogs: status quo and review of distribution, transmission, clinical findings, diagnostics and prophylaxis. Parasitol Res. (2015) 114:1954. doi: 10.1007/s00436-015-4513-0

58. Littman MP, Gerber B, Goldstein RE, Labato MA, Lappin MR, Moore GE. ACVIM consensus update on Lyme borreliosis in dogs and cats. J Vet Intern Med. (2018) 32:887-903. doi: 10.1111/jvim.15085

59. Lin Y-P, Diuk-Wasser MA, Stevenson B, Kraiczy P. Complement evasion contributes to Lyme borreliae-host associations. Trends Parasitol. (2020) 36:634-45. doi: 10.1016/j.pt.2020.04.011

60. Kurtenbach K, Sewell H-S, Ogden NH, Randolph SE, Nuttall PA. Serum complement sensitivity as a key factor in Lyme disease ecology. Infect Immun. (1998) 66:1248-51. doi: 10.1128/IAI.66.3.12481251.1998

61. Bhide MR, Travnicek M, Levkutova M, Curlik J, Revajova V, Levkut M. Sensitivity of Borrelia genospecies to serum complement from different animals and human: a host-pathogen relationship. FEMS Immunol Med Microbiol. (2005) 43:165-72. doi: 10.1016/j.femsim.200 4.07.012

62. Richter D, Matuschka F-R. Elimination of Lyme disease spirochetes from ticks feeding on domestic ruminants. Appl Environ Microbiol. (2010) 76:7650-2. doi: 10.1128/AEM.01649-10 
63. Lacombe E, Rand PW, Smith RP Jr. Disparity of Borrelia burgdorferi infection rates of adult Ixodes dammini on deer and vegetation. J Infect Dis. (1993) 167:1236-8. doi: 10.1093/infdis/16 7.5.1236

64. Ogden NH, Nuttall PA, Randolph SE. Natural Lyme disease cycles maintained via sheep by co-feeding ticks. Parasitology. (1997) 115:5919. doi: 10.1017/S0031182097001868

65. Burgess EC, Gendron-Fitzpatrick A, Wright WO. Arthritis and systemic disease caused by Borrelia burgdorferi infection in a cow. J Am Vet Med Assoc. (1987) 191:1468-70.

66. Lischer CJ, Leutenegger CM, Braun U, Lutz H. Diagnosis of Lyme disease in two cows by the detection of Borrelia burgdorferi DNA. Vet Rec. (2000) 146:497. doi: 10.1136/vr.146.17.497

67. Štefančíková A, Štěpánová G, Derdáková M, Pet'ko B, Kysel'ová J, Cigánek J, et al. Serological evidence for Borrelia burgdorferi infection associated with clinical signs in dairy cattle in Slovakia. Vet Res Commun. (2002) 26:601-11. doi: 10.1023/A:1020912618950

68. Tuomi J, Rantamäki LK, Tanskanen R. Experimental infection of cattle with several Borrelia burgdorferi sensu lato strains; immunological heterogeneity of strains as revealed in serological tests. Vet Microbiol. (1998) 60:2743. doi: 10.1016/S0378-1135(97)00200-9

69. Fridriksdóttir V, Overnes G, Stuen S. Suspected Lyme borreliosis in sheep. Vet Rec. (1992) 130:323-4. doi: 10.1136/vr.130.15.323

70. Stuen S, Fridriksdóttir V. Experimental inoculation of sheep with Borrelia burgdorferi. Vet Rec. (1991) 129:315. doi: 10.1136/vr.129.14.315

71. Hovmark A, Åsbrink E, Schwan O, Hederstedt B, Christensson D. Antibodies to Borrelia spirochetes in sera from Swedish cattle and sheep. Acta Vet Scand. (1986) 27:479-85.

72. Käsbohrer A, Schönberg A. Serologic studies of the occurrence of Borrelia burgdorferi in domestic animals in Berlin (West). Berl Munch Tierarztl Wochenschr. (1990) 103:374-8.

73. Cabannes A, Hernandez JC, Lucchese F, Appriou M, Tribouley-Duret J. Epidemiology of Lyme disease in cattle and sheep, in Gironde (France). Med Mal Infect. (1997) 27:878-83. doi: 10.1016/S0399-077X(97)80242-9

74. Štefančíková A, Derdáková M, Škardová I, Szestáková E, Cisláková L, Kováčová D, et al. Some epidemiological and epizootiological aspects of Lyme borreliosis in Slovakia with the emphasis on the problems of serological diagnostics. Biologia. (2008) 63:1135-42. doi: 10.2478/s11756-008-0177-x

75. Divers TJ. Equine Lyme disease. J Equine Vet Sci. (2013) 33:48892. doi: 10.1016/j.jevs.2013.03.187

76. Chang Y-F, Novosol V, McDonough SP, Chang C-F, Jacobson RH, Divers T, et al. Experimental infection of ponies with Borrelia burgdorferi by exposure to ixodid ticks. Vet Pathol. (2000) 37:68-76. doi: 10.1354/vp.37-1-68

77. Chang Y-F, Ku Y-W, Chang C-F, Chang C-D, McDonough SP, Divers T, et al. Antibiotic treatment of experimentally Borrelia burgdorferi-infected ponies. Vet Microbiol. (2005) 107:285-94. doi: 10.1016/j.vetmic.2005.02.006

78. James FM, Engiles JB, Beech J. Meningitis, cranial neuritis, and radiculoneuritis associated with Borrelia burgdorferi infection in a horse. $J$ Am Vet Med Assoc. (2010) 237:1180-5. doi: 10.2460/javma.237.10.1180

79. Imai DM, Barr BC, Daft B, Bertone JJ, Feng S, Hodzic E, et al. Lyme neuroborreliosis in 2 horses. Vet Pathol. (2011) 48:1151-7. doi: 10.1177/0300985811398246

80. Wagner B, Glaser A, Bartol J, Mahar O, Johnson A, Divers T. A new sensitive Lyme multiplex assay to confirm neuroborreliosis in horses: a case report. In: Proceedings of the 57th Annual Convention of the American Association of Equine Practitioners. San Antonio, TX: American Association of Equine Practitioners (AAEP) (2011). p. 70-5.

81. Pecoraro HL, Felippe MJB, Miller AD, Divers TJ, Simpson KW, Guyer KM, et al. Neuroborreliosis in a horse with common variable immunodeficiency. $J$ Vet Diagn Investig. (2019) 31:241-5. doi: 10.1177/1040638718824146

82. Maurizi L, Marié J-L, Aoun O, Courtin C, Gorsane S, Chal D, et al. Seroprevalence survey of equine Lyme borreliosis in France and in Sub-Saharan Africa. Vector Borne Zoonotic Dis. (2009) 10:5357. doi: $10.1089 / v b z .2009 .0083$

83. Appel MJG, Allan S, Jacobson RH, Lauderdale TL, Chang YF, Shin SJ, et al. Experimental Lyme disease in dogs produces arthritis and persistent infection. J Infect Dis. (1993) 167:651-4. doi: 10.1093/infdis/167.3.651
84. Chang Y-F, Novosel V, Chang C-F, Summers BA, Ma D-P, Chiang Y-W, et al. Experimental induction of chronic borreliosis in adult dogs exposed to Borrelia burgdorferi-infected ticks and treated with dexamethasone. Am J Vet Res. (2001) 62:1104-12. doi: 10.2460/ajvr.2001.62.1104

85. Summers BA, Straubinger AF, Jacobson RH, Chang YF, Appel MJG, Straubinger RK. Histopathological studies of experimental Lyme disease in the dog. J Compar Pathol. (2005) 133:1-13. doi: 10.1016/j.jcpa.2004.11.006

86. Speck S, Reiner B, Wittenbrink M. Isolation of Borrelia afzelii from dog. Vet Rec. (2001) 149:19-20. doi: 10.1136/vr.149.1.19

87. Hovius KE, Stark LA, Bleumink-Pluym NM, van de Pol I, Verbeek-de Kruif N, Rijpkema SG, et al. Presence and distribution of Borrelia burgdorferi sensu lato species in internal organs and skin of naturally infected symptomatic and asymptomatic dogs, as detected by polymerase chain reaction. Vet Q. (1999) 21:54-8. doi: 10.1080/01652176.1999.9694992

88. Skotarczak B, Wodecka B. Identification of Borrelia burgdorferi genospecies inducing Lyme disease in dogs from western Poland. Acta Vet Hung. (2005) 53:13-21. doi: 10.1556/avet.53.2005.1.2

89. Mather TN, Fish D, Coughlin RT. Competence of dogs as reservoirs for Lyme disease spirochetes (Borrelia burgdorferi). J Am Vet Med Assoc. (1994) 205:186-8.

90. Hovius KE. The protection of European dogs against infection with Lyme disease spirochaetes. In: Braks MAH, van Wieren SE, Takken W, Sprong $\mathrm{H}$, editors. Ecology and Prevention of Lyme borreliosis Ecology and Control of Vector-borne Diseases Vol 4. Wageningen, NL: Wageningen Academic Publishers (2016). p. 409-26.

91. Lappin MR, Chandrashekar R, Stillman B, Liu J, Mather TN. Evidence of Anaplasma phagocytophilum and Borrelia burgdorferi infection in cats after exposure to wild-caught adult Ixodes scapularis. J Vet Diagn Investig. (2015) 27:522-5. doi: 10.1177/1040638715593598

92. Burgess EC. Experimentally induced infection of cats with Borrelia burgdorferi. Am J Vet Res. (1992) 53:1507-11.

93. Tørnqvist-Johnsen C, Dickson S-A, Rolph K, Palermo V, HodgkissGeere H, Gilmore P, et al. First report of Lyme borreliosis leading to cardiac bradydysrhythmia in two cats. JFMS Open Reports. (2020) 6:16. doi: 10.1177/2055116919898292

94. Hoyt K, Chandrashekar R, Beall M, Leutenegger C, Lappin MR. Evidence for clinical anaplasmosis and borreliosis in cats in Maine. Top Companion Anim Med. (2018) 33:40-4. doi: 10.1053/j.tcam.2018.05.002

95. Liu Y, Nordone SK, Yabsley MJ, Lund RB, McMahan CS, Gettings JR. Quantifying the relationship between human Lyme disease and Borrelia burgdorferi exposure in domestic dogs. Geospat Health. (2019) 14:750. doi: 10.4081/gh.2019.750

96. Egenvall A, Bonnett BN, Gunnarsson A, Hedhammar A, Shoukri M, Bornstein S, et al. Sero-prevalence of granulocytic Ehrlichia spp. and Borrelia burgdorferi sensu lato in Swedish dogs 1991-94. Scand J Infect Dis. (2000) 32:19-25. doi: 10.1080/00365540050164164

97. Gerber B, Eichenberger S, Wittenbrink MM, Reusch CE. Increased prevalence of Borrelia burgdorferi infections in Bernese mountain dogs: a possible breed predisposition. BMC Vet Res. (2007) 3:15. doi: 10.1186/1746-6148-3-15

98. Preyß-Jägeler C, Müller E, Straubinger RK, Hartmann K. Prävalenz von Antikörpern gegen Borrelia burgdorferi, Anaplasma phagocytophilum und bestimmte Leptospira-interrogans-Serovare bei Berner Sennenhunden. Tierarztl Prax Ausg K Kleintiere Heimtiere. (2016) 44:77-85. doi: 10.15654/TPK-140962

99. Barth C, Straubinger RK, Sauter-Louis C, Hartmann K. Prevalence of antibodies against Borrelia burgdorferi sensu lato and Anaplasma phagocytophilum and their clinical relevance in dogs in Munich, Germany. Berl Munch Tierarztl Wochenschr. (2012) 125:337-44. doi: 10.2376/0005-9366-125-337

100. Kybicová K, Schánilec P, Hulínská D, Uherková L, Kurzová Z, Spejchalová S. Detection of Anaplasma phagocytophilum and Borrelia burgdorferi sensu lato in dogs in the Czech Republic. Vector Borne Zoonotic Dis. (2009) 9:655-61. doi: 10.1089/vbz.2008.0127

101. Pantchev N, Vrhovec MG, Pluta S, Straubinger RK. Seropositivity of Borrelia burgdorferi in a cohort of symptomatic cats from Europe based on a C6peptide assay with discussion of implications in disease aetiology. Berl Munch Tierarztl Wochenschr. (2016) 129:333-9. doi: 10.2376/0005-9366-15088 
102. Žákovská A, Schánilec P, Treml F, Dušková M, Agudelo RCF. Seroprevalence of antibodies against Borrelia burgdorferi s. 1 and Leptospira interrogans s. I. in cats in district of Brno and its environs, the Czech Republic. Ann Agric Environ Med. (2020) 27:356-60. doi: 10.26444/aaem/122804

103. Shaw SE, Binns SH, Birtles RJ, Day MJ, Smithson RC, Kenny MJ. Molecular evidence of tick-transmitted infections in dogs and cats in the United Kingdom. Vet Rec. (2005) 157:645. doi: 10.1136/vr.157.21.645

104. Cutler S, Vayssier-Taussat M, Estrada-Peña A, Potkonjak A, Mihalca AD, Zeller H. A new Borrelia on the block: Borrelia miyamotoi - a human health risk? Eurosurveillance. (2019) 24:1800170. doi: 10.2807/1560-7917.ES.2019.24.18.1800170

105. Gugliotta JL, Goethert HK, Berardi VP, Telford SR 3rd. Meningoencephalitis from Borrelia miyamotoi in an immunocompromised patient. N Engl J Med. (2013) 368:240-5. doi: 10.1056/NEJMoa1209039

106. Boden K, Lobenstein S, Hermann B, Margos G, Fingerle V. Borrelia miyamotoi-associated neuroborreliosis in immunocompromised person. Emerg Infect Dis. (2016) 22:1617-20. doi: 10.3201/eid2209.152034

107. Richter D, Matuschka F-R. Modulatory effect of cattle on risk for Lyme disease. Emerg Infect Dis. (2006) 12:1919-23. doi: 10.3201/eid1212.051552

108. Shannon AB, Rucinsky R, Gaff HD, Brinkerhoff RJ. Borrelia miyamotoi, other vector-borne agents in cat blood and ticks in Eastern Maryland. EcoHealth. (2017) 14:816-20. doi: 10.1007/s10393-017-1268-3

109. Dugat T, Lagree AC, Maillard R, Boulouis HJ, Haddad N. Opening the black box of Anaplasma phagocytophilum diversity: current situation and future perspectives. Front Cell Infect Microbiol. (2015) 5:61. doi: 10.3389/fcimb.2015.00061

110. Dumler JS, Choi K-S, Garcia-Garcia JC, Barat NS, Scorpio DG, Garyu JW, et al. Human granulocytic anaplasmosis and Anaplasma phagocytophilum. Emerg Infect Dis. (2005) 11:1828-34. doi: 10.3201/eid1112.050898

111. Jaarsma RI, Sprong H, Takumi K, Kazimirova M, Silaghi C, Mysterud A, et al. Anaplasma phagocytophilum evolves in geographical and biotic niches of vertebrates and ticks. Parasit Vectors. (2019) 12:328. doi: 10.1186/s13071-019-3583-8

112. Brown WC. Adaptive immunity to Anaplasma pathogens and immune dysregulation: implications for bacterial persistence. Comp Immunol Microbiol Infect Dis. (2012) 35:241-52. doi: 10.1016/j.cimid.2011.12.002

113. Stuen S, Nevland S, Moum T. Fatal cases of tick-borne fever (TBF) in sheep caused by several 16S rRNA gene variants of Anaplasma phagocytophilum. Ann N Y Acad Sci. (2003) 990:433-4. doi: 10.1111/j.1749-6632.2003.tb07407.x

114. Stuen S, Braten M, Bergström K, Bardsen K. Cyclic variation in lambs infected with Anaplasma phagocytophilum. Vet Rec. (2008) 163:3389. doi: $10.1136 /$ vr.163.11.338

115. Thomas RJ, Birtles RJ, Radford AD, Woldehiwet Z. Recurrent bacteraemia in sheep infected persistently with Anaplasma phagocytophilum. J Compar Pathol. (2012) 147:360-7. doi: 10.1016/j.jcpa.2012.02.005

116. Lagrée A-C, Rouxel C, Kevin M, Dugat T, Girault G, Durand B, et al. Co-circulation of different $A$. phagocytophilum variants within cattle herds and possible reservoir role for cattle. Parasit Vectors. (2018) 11:163. doi: 10.1186/s13071-018-2661-7

117. Scharf W, Schauer S, Freyburger F, Petrovec M, Schaarschmidt-Kiener D, Liebisch G, et al. Distinct host species correlate with Anaplasma phagocytophilum ankA gene clusters. J Clin Microbiol. (2011) 49:7906. doi: 10.1128/JCM.02051-10

118. Hulínská D, Langrová K, Pejčoch M, Pavlásek I. Detection of Anaplasma phagocytophilum in animals by real-time polymerase chain reaction. APMIS. (2004) 112:239-47. doi: 10.1111/j.1600-0463.2004.apm11204-0503.x

119. Stuen S, Oppegaard AS, Bergström K, Moum T. Anaplasma phagocytophilum infection in north Norway. The first laboratory confirmed case. Acta Vet Scand. (2005) 46:167. doi: 10.1186/1751-0147-46-167

120. Pusterla N, Pusterla JB, Braun U, Lutz H. Serological, hematologic and PCR studies of cattle in an area of Switzerland in which tick-borne fever (caused by Ehrlichia phagocytophila) is endemic. Clin Diagn Lab Immunol. (1998) 5:325-7. doi: 10.1128/CDLI.5.3.325-327.1998

121. Engvall EO, Pettersson B, Persson M, Artursson K, Johansson KE. A 16S rRNA-based PCR assay for detection and identification of granulocytic Ehrlichia species in dogs, horses, and cattle. J Clin Microbiol. (1996) 34:21704. doi: 10.1128/JCM.34.9.2170-2174.1996
122. Stuen S, Bergström K. Serological investigation of granulocytic Ehrlichia infection in sheep in Norway. Acta Vet Scand. (2001) 42:331-8. doi: 10.1186/1751-0147-42-331

123. Zeman P, Januska J, Orolinova M, Stuen S, Struhar V, Jebavy L. High seroprevalence of granulocytic ehrlichiosis distinguishes sheep that were the source of an alimentary epidemic of tick-borne encephalitis. Wien Klin Wochenschr. (2004) 116:614-6. doi: 10.1007/s00508-004-0191-0

124. Derdáková M, Štefančíková A, Špitalská E, Taragelová V, Koštálová T, Hrklová G, et al. Emergence and genetic variability of Anaplasma species in small ruminants and ticks from central Europe. Vet Microbiol. (2011) 153:293-8. doi: 10.1016/j.vetmic.2011.05.044

125. Silaghi C, Scheuerle MC, Friche Passos LM, Thiel C, Pfister K. PCR detection of Anaplasma phagocytophilum in goat flocks in an area endemic for tick-borne fever in Switzerland. Parasite. (2011) 18:5762. doi: 10.1051/parasite/2011181057

126. Harrison A, Brown KJ, Ian Montgomery W. Anaplasma phagocytophilum in feral goats in Northern Ireland. Vet Rec. (2012) 170:602-3. doi: 10.1136/vr.e3938

127. Dreher UM, de la Fuente J, Hofmann-Lehmann R, Meli ML, Pusterla N, Kocan KM, et al. Serologic cross-reactivity between Anaplasma marginale and Anaplasma phagocytophilum. Clin Diagn Lab Immunol. (2005) 12:117783. doi: 10.1128/CDLI.12.10.1177-1183.2005

128. de la Fuente J, Lew A, Lutz H, Meli ML, Hofmann-Lehmann R, Shkap V, et al. Genetic diversity of Anaplasma species major surface proteins and implications for anaplasmosis serodiagnosis and vaccine development. Anim Health Res Rev. (2005) 6:75-89. doi: 10.1079/AHR2005104

129. Hornok S, Micsutka A, Fernández de Mera IG, Meli ML, Gönczi E, Tánczos $B$, et al. Fatal bovine anaplasmosis in a herd with new genotypes of Anaplasma marginale, Anaplasma ovis and concurrent haemoplasmosis. Res Vet Sci. (2012) 92:30-5. doi: 10.1016/j.rvsc.2010.10.011

130. Dahmani M, Davoust B, Rousseau F, Raoult D, Fenollar F, Mediannikov O. Natural Anaplasmataceae infection in Rhipicephalus bursa ticks collected from sheep in the French Basque country. Ticks Tick Borne Dis. (2017) 8:18-24. doi: 10.1016/j.ttbdis.2016.09.009

131. Saleem S, Ijaz M, Farooqi SH, Ghaffar A, Ali A, Iqbal K, et al. Equine granulocytic anaplasmosis 28 years later. Microbial Pathog. (2018) 119:18. doi: 10.1016/j.micpath.2018.04.001

132. Franzén P, Aspan A, Egenvall A, Gunnarsson A, Karlstam E, Pringle J. Molecular evidence for persistence of Anaplasma phagocytophilum in the absence of clinical abnormalities in horses after recovery from acute experimental infection. J Vet Intern Med. (2009) 23:636-42. doi: 10.1111/j.1939-1676.2009.0317.x

133. Zeman P, Jahn P. An entropy-optimized multilocus approach for characterizing the strains of Anaplasma phagocytophilum infecting horses in the Czech Republic. J Med Microbiol. (2009) 58:423-9. doi: 10.1099/jmm.0.007831-0

134. Bretscher R. Serologische Untersuchungen zur Häufigkeit und Verbreitung der equinen Ehrlichiose in der Schweiz. Schweiz Arch Tierheilkd. (1991) 133:185.

135. Praskova I, Bezdekova B, Zeman P, Jahn P. Seroprevalence of Anaplasma phagocytophilum in horses in the Czech Republic. Ticks Tick Borne Dis. (2011) 2:111-5. doi: 10.1016/j.ttbdis.2011.01.002

136. Slivinska K, Víchová B, Werszko J, Szewczyk T, Wróblewski Z, Petko B, et al. Molecular surveillance of Theileria equi and Anaplasma phagocytophilum infections in horses from Ukraine, Poland and Slovakia. Vet Parasitol. (2016) 215:35-7. doi: 10.1016/j.vetpar.2015.10.025

137. Sainz Á, Roura X, Miró G, Estrada-Peña A, Kohn B, Harrus S, et al. Guideline for veterinary practitioners on canine ehrlichiosis and anaplasmosis in Europe. Parasit Vectors. (2015) 8:75. doi: 10.1186/s13071-0150649-0

138. Pennisi MG, Hofmann-Lehmann R, Radford AD, Tasker S, Belák S, Addie DD, et al. Anaplasma, Ehrlichia and Rickettsia species infections in cats: European guidelines from the $\mathrm{ABCD}$ on prevention and management. J Feline Med Surg. (2017) 19:542-8. doi: 10.1177/1098612X177 06462

139. Egenvall A, Lilliehöök I, Bjöersdorff A, Engvall EO, Karlstam E, Artursson K, et al. Detection of granulocytic Ehrlichia species DNA by PCR in persistently infected dogs. Vet Rec. (2000) 146:186-90. doi: 10.1136/vr.146.7.186 
140. Kirtz G, Czettel B, Thum D, Leidinger E. Anaplasma phagocytophilum in einer österreischichen Hundepopulation: eine Prävalenz-Studie (20012006). Kleintierpraxis. (2007) 7:562-8.

141. Egenvall A, Franzén P, Gunnarsson A, Engvall EO, Vågsholm I, Wikström U-B, et al. Cross-sectional study of the seroprevalence to Borrelia burgdorferi sensu lato and granulocytic Ehrlichia spp. and demographic, clinical and tick-exposure factors in Swedish horses. Prev Vet Med. (2001) 49:191208. doi: 10.1016/S0167-5877(01)00187-8

142. Hofmann-Lehmann R, Wagmann N, Meli ML, Riond B, Novacco M, Joekel D, et al. Detection of Candidatus Neoehrlichia mikurensis and other Anaplasmataceae and Rickettsiaceae in Canidae in Switzerland and Mediterranean countries. Schweiz Arch Tierheilkd. (2016) 158:691700. doi: $10.17236 /$ sat 00087

143. Bajer A, Mierzejewska EJ, Rodo A, Bednarska M, Kowalec M, WelcFaleciak R. The risk of vector-borne infections in sled dogs associated with existing and new endemic areas in Poland: part 1: a population study on sled dogs during the racing season. Vet Parasitol. (2014) 202:27686. doi: 10.1016/j.vetpar.2013.12.033

144. Berzina I, Capligina V, Bormane A, Pavulina A, Baumanis V, Ranka R, et al. Association between Anaplasma phagocytophilum seroprevalence in dogs and distribution of Ixodes ricinus and Ixodes persulcatus ticks in Latvia. Ticks Tick Borne Dis. (2013) 4:83-8. doi: 10.1016/j.ttbdis.2012.08.003

145. Morgenthal D, Hamel D, Arndt G, Silaghi C, Pfister K, Kempf VAJ, et al. Prävalenz von hämotrophen Mycoplasma spp., Bartonella spp. und Anaplasma phagocytophilum bei Katzen im Raum Berlin/Brandenburg. Berl Munch Tierarztl Wochenschr. (2012) 125:418-27. doi: 10.2376/0005-9366-125-11

146. Hamel D, Bondarenko A, Silaghi C, Nolte I, Pfister K. Seroprevalence and bacteremia [corrected] of Anaplasma phagocytophilum in cats from Bavaria and Lower Saxony (Germany). Berl Munch Tierarztl Wochenschr. (2012) 125:163-7. doi: 10.2371/0005-9311-125-113

147. Krücken J, Schreiber C, Maaz D, Kohn M, Demeler J, Beck S, et al. A novel high-resolution melt PCR assay discriminates Anaplasma phagocytophilum and Candidatus Neoehrlichia mikurensis. J Clin Microbiol. (2013) 51:195861. doi: 10.1128/JCM.00284-13

148. Wass L, Grankvist A, Bell-Sakyi L, Bergström M, Ulfhammer E, Lingblom $\mathrm{C}$, et al. Cultivation of the causative agent of human neoehrlichiosis from clinical isolates identifies vascular endothelium as a target of infection. Emerg Microbes Infect. (2019) 8:413-25. doi: 10.1080/22221751.2019.1584017

149. Portillo A, Santibáñez P, Palomar AM, Santibáñez S, Oteo JA. Candidatus Neoehrlichia mikurensis in Europe. New Microbes New Infect. (2018) 22:306. doi: 10.1016/j.nmni.2017.12.011

150. Beck A, Huber D, Antolić M, Anzulović Ž, Reil I, Polkinghorne A, et al. Retrospective study of canine infectious haemolytic anaemia cases reveals the importance of molecular investigation in accurate postmortal diagnostic protocols. Comp Immunol Microbiol Infect Dis. (2019) 65:817. doi: 10.1016/j.cimid.2019.05.006

151. Liesner JM, Krücken J, Schaper R, Pachnicke S, Kohn B, Müller E, et al. Vector-borne pathogens in dogs and red foxes from the federal state of Brandenburg, Germany. Vet Parasitol. (2016) 224:4451. doi: 10.1016/j.vetpar.2016.05.012

152. Hornok S, Horváth G, Takács N, Farkas R, Szoke K, Kontschán J. Molecular evidence of a badger-associated Ehrlichia sp., a Candidatus Neoehrlichia lotoris-like genotype and Anaplasma marginale in dogs. Ticks Tick Borne Dis. (2018) 9:1302-9. doi: 10.1016/j.ttbdis.2018.05.012

153. Oteo JA, Portillo A. Tick-borne rickettsioses in Europe. Ticks Tick Borne Dis. (2012) 3:271-8. doi: 10.1016/j.ttbdis.2012.10.035

154. Azagi T, Hoornstra D, Kremer K, Hovius JWR, Sprong H. Evaluation of disease causality of rare Ixodes ricinus-borne infections in Europe. Pathogens. (2020) 9:150. doi: 10.3390/pathogens 9020150

155. Keenan KP, Buhles WC, Huxsoll DL, Williams RG, Hildebrandt PK. Studies on the pathogenesis of Rickettsia rickettsii in the dog: clinical and clinicopathologic changes of experimental infection. Am J Vet Res. (1977) 38:851-6.

156. Solano-Gallego L, Kidd L, Trotta M, Di Marco M, Caldin M, Furlanello T, et al. Febrile illness associated with Rickettsia conorii infection in dogs from Sicily. Emerg Infect Dis. (2006) 12:1985-8. doi: 10.3201/eid1212.060326
157. Levin ML, Killmaster LF, Zemtsova GE. Domestic dogs (Canis familiaris) as reservoir hosts for Rickettsia conorii. Vector Borne Zoonotic Dis. (2011) 12:28-33. doi: 10.1089/vbz.2011.0684

158. Elfving K, Malmsten J, Dalin A-M, Nilsson K. Serologic and molecular prevalence of Rickettsia helvetica and Anaplasma phagocytophilum in wild cervids and domestic mammals in the central parts of Sweden. Vector Borne Zoonotic Dis. (2015) 15:529-34. doi: 10.1089/vbz.2015.1768

159. Wächter M, Pfeffer M, Schulz N, Balling A, Chirek A, Bach JP, et al. Seroprevalence of spotted fever group Rickettsiae in dogs in Germany. Vector Borne Zoonotic Dis. (2015) 15:191-4. doi: 10.1089/vbz.2014.1715

160. Wächter M, Wölfel S, Pfeffer M, Dobler G, Kohn B, Moritz A, et al. Serological differentiation of antibodies against Rickettsia helvetica, $R$. raoultii, $R$. slovaca, $R$. monacensis and $R$. felis in dogs from Germany by a micro-immunofluorescent antibody test. Parasit Vectors. (2015) 8:126. doi: 10.1186/s13071-015-0745-1

161. Rymaszewska A, Małgorzata A. Molecular evidence of vector-borne pathogens coinfecting dogs from Poland. Acta Vet Hung. (2011) 59:215. doi: 10.1556/avet.2011.008

162. Boretti FS, Perreten A, Meli ML, Cattori V, Willi B, Wengi N, et al. Molecular investigations of Rickettsia helvetica infection in dogs, foxes, humans, and Ixodes ticks. Appl Environ Microbiol. (2009) 75:32307. doi: 10.1128/AEM.00220-09

163. Juvet F, Lappin MR, Brennan S, Mooney CT. Prevalence of selected infectious agents in cats in Ireland. J Feline Med Surg. (2010) 12:47682. doi: 10.1016/j.jfms.2010.02.003

164. Spada E, Proverbio D, Galluzzo P, Perego R, Bagnagatti De Giorgi G, Roggero N, et al. Frequency of piroplasms Babesia microti and Cytauxzoon felis in stray cats from northern Italy. Biomed Res Int. (2014) 2014:943754. doi: 10.1155/2014/943754

165. Zintl A, Mulcahy G, Skerrett HE, Taylor SM, Gray JS. Babesia divergens, a bovine blood parasite of veterinary and zoonotic importance. Clin Microbiol Rev. (2003) 16:622-36. doi: 10.1128/CMR.16.4.622-6 36.2003

166. Springer A, Höltershinken M, Lienhart F, Ermel S, Rehage J, Hülskötter $\mathrm{K}$, et al. Emergence and epidemiology of bovine babesiosis due to Babesia divergens on a northern German beef production farm. Front Vet Sci. (2020) 7:649. doi: 10.3389/fvets.2020.00649

167. Gern L, Kindler A, Brossard M. Annual evolution of cattle immunity against Babesia divergens in northern Switzerland. Prev Vet Med. (1988) 6:9-16. doi: 10.1016/0167-5877(88)90021-9

168. Zintl A, Gray JS, Skerrett HE, Mulcahy G. Possible mechanisms underlying age-related resistance to bovine babesiosis. Parasite Immunol. (2005) 27:11520. doi: 10.1111/j.1365-3024.2005.00748.x

169. Losson B, Lefevre F. La babesiose bovine en Belgique. Une enquête sérologique en zone d'endémie. Ann Med Vet. (1989) 133:421-6.

170. Lempereur L, Lebrun M, Cuvelier P, Sépult G, Caron Y, Saegerman $\mathrm{C}$, et al. Longitudinal field study on bovine Babesia spp. and Anaplasma phagocytophilum infections during a grazing season in Belgium. Parasitol Res. (2012) 110:1525-30. doi: 10.1007/s00436-0112657-0

171. L'Hostis M, Chauvin A, Valentin A, Precigout E, Gorenflot A. Survey of Babesia divergens antibody kinetics in cattle in western France. Vet Res. (1997) 28:481-8.

172. Malandrin L, L'Hostis M, Chauvin A. Isolation of Babesia divergens from carrier cattle blood using in vitro culture. Vet Res. (2004) 35:1319. doi: 10.1051/vetres:2003047

173. Devos J, Geysen D. Epidemiological study of the prevalence of Babesia divergens in a veterinary practice in the mid-east of France. Vet Parasitol. (2004) 125:237-49. doi: 10.1016/j.vetpar.2004.08.004

174. Agoulon A, Malandrin L, Lepigeon F, Vénisse M, Bonnet S, Becker $\mathrm{CAM}$, et al. A vegetation index qualifying pasture edges is related to Ixodes ricinus density and to Babesia divergens seroprevalence in dairy cattle herds. Vet Parasitol. (2012) 185:101-9. doi: 10.1016/j.vetpar.201 1.10 .022

175. Ullmann B. Untersuchungen zum Vorkommen und zur serologischen Differenzierung von Babesien bei Rindern im westlichen Allgäu (Dissertation). Ludwig-Maximilians-Universität München, Munich, Germany (1983). 
176. Ganse-Dumrath D, Hannover TH. Epidemiology of Babesia divergens infection in cattle in northern Germany (Dissertation). Univerisity of Veterinary Medicine Hannover, Hanover, Germany (1986).

177. Niepold J. Untersuchung von Rinderseren auf das simultane Vorkommen von Infektionen mit Borrelien (Borrelia burgdorferi) und Babesien (Babesia divergens). (Dissertation). University of Veterinary Medicine Hannover, Hanover, Germany (1990).

178. Lengauer H, Just FT, Edelhofer R, Pfister K. Tick infestation and the prevalence of Borrelia burgdorferi and Babesia divergens in cattle in Bavaria. Berl Munch Tierarztl Wochenschr. (2006) 119:335-41.

179. Hornok S, Edelhofer R, Szotáczky I, Hajtós I. Babesia divergens becoming extinct in cattle of northeast Hungary: new data on the past and present situation. Acta Vet Hung. (2006) 54:493-501. doi: 10.1556/AVet.54.2006.4.7

180. Hasle G, Bjune GA, Christensson D, Røed KH, Whist AC, Leinaas HP. Detection of Babesia divergens in southern Norway by using an immunofluorescence antibody test in cow sera. Acta Vet Scand. (2010) 52:55. doi: 10.1186/1751-0147-52-55

181. Andersson MO, Víchová B, Tolf C, Krzyzanowska S, Waldenström J, Karlsson ME. Co-infection with Babesia divergens and Anaplasma phagocytophilum in cattle (Bos taurus), Sweden. Ticks Tick Borne Dis. (2017) 8:933-5. doi: 10.1016/j.ttbdis.2017.08.005

182. Adam KMG, Blewett DA, Collins TJ, Edgar JT. Outbreaks of babesiasis on two farms in Scotland. Br Vet J. (1978) 134:428-33. doi: 10.1016/S0007-1935(17)33384-5

183. Adam KM, Blewett DA. A serological survey for Babesia in cattle in Scotland II. The occurrence of antibody in the population and the distribution of infected herds. Ann Trop Med Parasitol. (1978) 72:41728. doi: 10.1080/00034983.1978.11719342
184. Taylor SM, Kenny J, Strain A. The distribution of Babesia divergens infection within the cattle population of Northern Ireland. Br Vet J. (1982) 138:38492. doi: 10.1016/S0007-1935(17)30983-1

185. Gray A, Capewell P, Loney C, Katzer F, Shiels BR, Weir W. Sheep as host species for zoonotic Babesia venatorum, United Kingdom. Emerg Infect Dis. (2019) 25:2257-60. doi: 10.3201/eid2512.190459

186. Zintl A, McGrath G, O'Grady L, Fanning J, Downing K, Roche D, et al Changing incidence of bovine babesiosis in Ireland. Ir Vet J. (2014) 67:7. doi: 10.1186/2046-0481-67-19

187. Chauvin A, Moreau E, Bonnet S, Plantard O, Malandrin L. Babesia and its hosts: adaptation to long-lasting interactions as a way to achieve efficient transmission. Vet Res. (2009) 40:37. doi: 10.1051/vetres/ 2009020

188. Johnson RC, Schmid GP, Hyde FW, Steigerwalt AG, Brenner DJ. Borrelia burgdorferi sp. nov.: etiologic agent of Lyme disease. Int J Syst Evol Microbiol. (1984) 34:496-7. doi: 10.1099/00207713-34-4-496

Conflict of Interest: The authors declare that the research was conducted in the absence of any commercial or financial relationships that could be construed as a potential conflict of interest.

Copyright (c) 2020 Springer, Glass, Topp and Strube. This is an open-access article distributed under the terms of the Creative Commons Attribution License (CC BY). The use, distribution or reproduction in other forums is permitted, provided the original author(s) and the copyright owner(s) are credited and that the original publication in this journal is cited, in accordance with accepted academic practice. No use, distribution or reproduction is permitted which does not comply with these terms. 